\title{
Las etnias amazónicas del departamento del Cusco
}

Department of Cusco Amazonian Ethnic Groups

Alfredo Ugarte Vega Centeno* http://dx.doi.org/10.21503/lex.v11i11.15

\begin{abstract}
Antropólogo, experto en Pueblos Indígenas. Trabajó en el Convenio Perú- Holanda (Proyecto de Desarrollo Rural en Microrregiones), Instituto de Manejo del Agua y del Medio Ambiente (IMA), Pro Naturaleza (Parque Nacional del Manu), Pro Naturaleza (Parque Nacional Babuaja Sonene), Pro Naturaleza (Camisea), Centro de Investigación y Promoción Amazónica (CIPA). Entre las consultorías que ha realizado está la Formulación del IMA (Nederland Economist Institute NEI), Plan de Monitoreo Ambiental Comunitario PMAC en Camisea - Domus Pro Naturaleza, Protección del Bajo Urubamba ( INRENA), Plan Maestro de la Reserva Comunal Machigüenga (SERNAMP) y Plan Maestro del Santuario Histórico de Machu Picchu (SERNAMP).
\end{abstract}

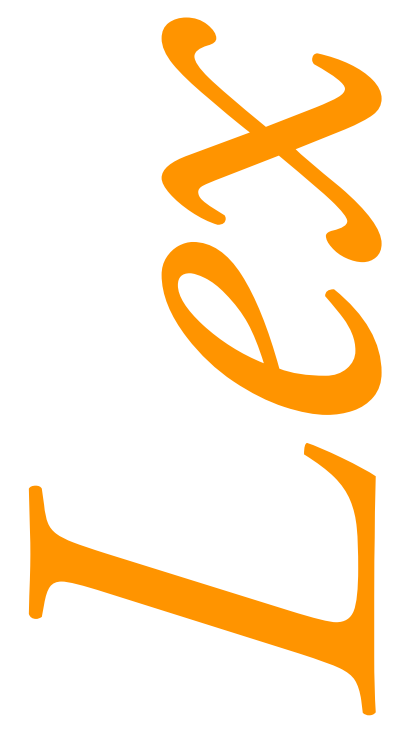




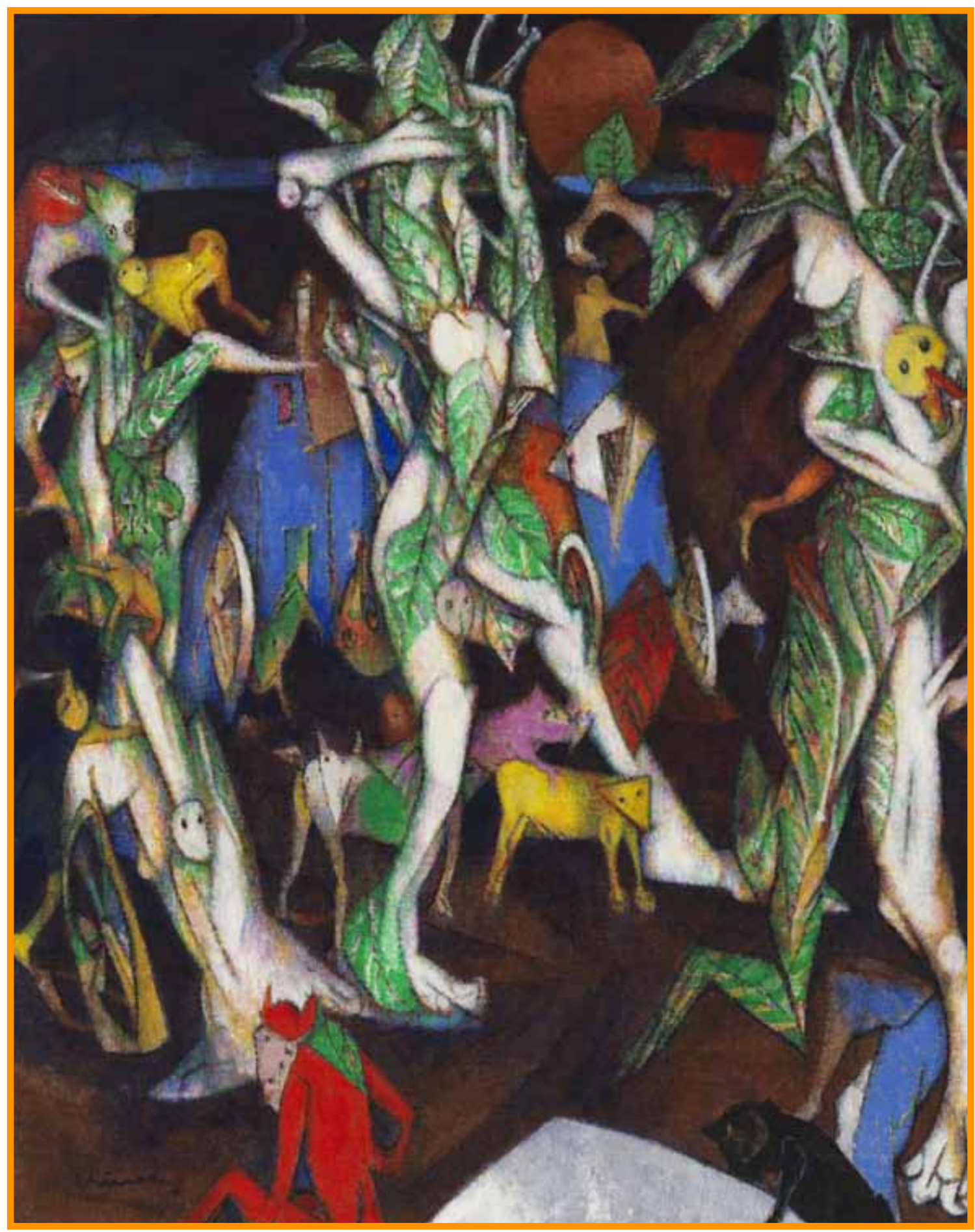

Paisajes del inconsciente III. (1990) 


\section{RESUMEN}

Mi interés al escribir sobre las comunidades nativas del departamento del Cusco fue netamente académico. Contribuir desde la antropología al conocimiento de su realidad y mostrar al Cusco no solo como un departamento andino sino también amazónico era importante para resolver su problemática, porque lo andino tiene un peso histórico bastante grande al haber sido Cusco capital del Imperio Inca, proyecto que abarcó casi todo el continente sudamericano y ser en la actualidad el único proyecto que permitió tener a nuestra querida tierra en una dimensión continental. Decir que Cusco es la capital de lo "andino" en el presente es señalar que es prisionero de su historia, lo que se reflejaba en la distribución nada equitativa de los presupuestos hacia su zona amazónica, concentrándose en las zonas andinas. Los sectores amazónicos del departamento se debatían entre la pobreza, el olvido y la indiferencia. Uno de los factores que contribuían a este comportamiento fue la ignorancia y la falta de propuestas de su clase política, desconocimiento y olvido, también desde la ciudadanía cusqueña, que calificaba a sus paisanos amazónicos despectivamente como "chunchos" (salvajes), pero también provenía de la universidad. Demostrar que más de la mitad del Departamento en términos superficiales es amazónico y que en ella viven comunidades, etnias y familias lingüísticas es todavía un desafío que se encuentra pendiente y que debe cambiar al asumir un autorreconocimiento de ser un departamento andino amazónico, tan rico en historial como la parte andina, le permitirá asumir un enfoque diferente al actual. El documento se trabajó mediante un enfoque de cuenca que nos permitió ubicar los principales ríos y el lugar donde se encuentran las comunidades nativas y su relación con las familias lingüísticas y grupos étnicos al que pertenecían. Paralelamente, los ubicamos en su respectiva jurisdicción política, es decir, en sus respectivos distritos y provincias, para finalmente realizar una breve descripción histórica y antropológica de cada etnia que permita al lector ubicarse en la problemática.

Seguramente también será un aporte para la importante Ley de Consulta que aprobó el actual Gobierno, y cuyo reglamento hasta la fecha no se aprueba, por haberse perdido el norte en la elaboración de una "línea base" de las comunidades por un sector burocrático del aparato estatal, temeroso de las presiones políticas y económicas. Esta elaboración debería realizarse en forma académica y científica al margen de la política y sus intereses.

Palabras clave: etnia, comunidad nativa, Amazonía, familia lingüistica. 


\begin{abstract}
My interest in writing about the native communities in Cusco Region was purely academic to contribute from anthropology to the knowledge of their reality and show Cusco not only as an Andean Department but also Amazon area, was important to solve their problems, because the Andean has a fairly large historical weight having been capital Cusco of the Inca Empire, project that it covered almost all of the South American continent and today being the only project, that allowed to have our beloved land a continental dimension. To say that Cusco is capital of "Andean" in the present, it is noted that it is a prisoner of its history and was reflected in nothing equitable distribution of budgets towards its Amazonian zone, concentrating in the Andean regions. The Amazonian areas of the Department were discussed poverty, forgetfulness and indifference. One of the factors contributing to this behavior was ignorance and the lack of proposals of its political class, ignorance and oblivion also citizenship from Cusco, which qualify to his Amazonian countrymen derogatorily as "chunchos" (wild), but also came from the University. Show that more than half of the Department in superficial terms is Amazon and in itself living communities, ethnic group and linguistic families is still a challenge that is pending and that must change to take a self-recognition of an Andean-Amazonian Region, so rich in history as Andean, attitude will allow it to take a different approach in comparison with the current reality. The document will work through an approach of watershed that allowed us to locate the main rivers and the place where are the native communities and their relationship with the linguistic families and ethnic groups to which they belonged. At the same time, we located them in their respective jurisdiction, that is, in their respective districts and provinces, to finally make a brief historical and anthropological of each ethnic group that let the reader located in the problem.

Surely it will also be a contribution to important law Ley de Consulta that adopted the current government whose regulation so far is not approved, because it has been lost direction in the elaboration of a "baseline" of communities by a bureaucratic sector of the device state, fearing political and economic pressures. This development should be done in academic and scientific way aside from politics and interests.
\end{abstract}

Key words: ethnic group, native community, Amazonía, language family. 


\section{INTRODUCCIÓN}

Según la arqueología, el poblamiento de nuestro continente americano y en particular de nuestro país comenzó entre unos veinticinco mil a treinta mil años atrás, por dos corrientes migratorias que se han identificado plenamente, una que proviene de Oceanía, y otra, la mongoloide, la más importante, que pasa por el estrecho de Bering, formándose dos corrientes que han producido un intenso debate sobre los orígenes de la cultura americana y en particular de la peruana.

Este paisaje cultural ha cambiado a partir del siglo XVI con la llegada de los españoles a nuestro continente y nuestra incorporación como colonia a España y su "articulación con Occidente", que se amplió en los albores de la República con la llegada de esclavos negros y de una importante corriente migratoria china, japonesa y de diversos grupos humanos en el siglo XX, como efecto de la "globalización", produciéndose así un intenso "mestizaje".

El Perú tiene en la actualidad una realidad cultural y lingüística heterogénea, pluricultural y multilingüe, que se expresa en la coexistencia de unas 72 etnias, aproximadamente, pertenecientes a unas 15 familias lingüísticas. Decimos aproximadamente porque entre lingüistas, antropólogos y otros especialistas existe un intenso debate sobre la composición de las mismas, y entre una y otra clasificación existen muchas diferencias.

En la Colonia, principalmente los misioneros dominicos y franciscanos se dedicaron al estudio de las lenguas que existían en nuestro territorio con fines de evangelización de los pueblos originarios, escribiendo diccionarios, gramáticas y ortografías de las diferentes lenguas, traduciendo textos bíblicos, catecismos y libros de oraciones a los idiomas indígenas; así mismo se escribieron en ese período las primeras gramáticas del quechua, aimara y puquina, o las más recientes en el siglo XX por parte de las iglesias evangélicas mediante el Instituto Lingüístico de Verano (ILV) sobre las lenguas amazónicas, como el matsigüenka, yine, caquinte o el asháninca, que son valioso testimonio para los trabajos científicos que se desarrollan en el presente sobre la diversas lenguas que existen en nuestro territorio. 
Un aporte importante se da a partir de 1940 desde la antropología y la lingüística, que comenzaron a realizar estudios orientados hacia los idiomas ágrafos, especialmente de las culturas de nuestra Amazonía, considerándose como un punto de partida para los trabajos científicos en esta rama y que ha cubierto en la actualidad a casi todas las lenguas de las familias lingüísticas que viven en nuestro país. En la actualidad existen publicaciones sobre gramática, diccionarios, cuentos en los idiomas originarios, pero falta formalizar y oficializar los alfabetos de las lenguas indígenas, que sería un gran avance para desarrollar la alfabetización y la educación bilingüe, pues permitiría fortalecer y desarrollar la identidad étnica y cultural de nuestro país.

El siguiente cuadro es una aproximación a esta compleja problemática de las familias lingüísticas. Muestra siete grupos étnicos en el área andina y a 65 del área amazónica. Para comprender mejor el cuadro señalemos que etnia es una población con cultura y lengua propias, y que familia lingüistica llamamos al conjunto de lenguas emparentadas entre sí. Las etnias indígenas conservan al interior de sí sus tradiciones, creencias, prácticas socioculturales y económicas, lo cual les confiere una identidad y una posibilidad de diferenciación entre un grupo y otro.

\section{Cuadro 1}

ETNIAS DEL PERÚ SEGÚN FAMILIAS LINGÜÍSTICAS

\begin{tabular}{|c|c|}
\hline $\begin{array}{c}\text { FAMILIAS } \\
\text { LINGÜÍSTICAS }\end{array}$ & ETNIA \\
\hline I. CASTELLANO & \\
\hline II. QUECHUA & 08 Grupos étnicos \\
\hline III. ARU & 02 Grupos étnicos \\
\hline IV. ARAHUACA & 13 Grupos étnicos \\
\hline V. JÍBARO & 06 Grupos étnicos \\
\hline VI. PANO & 14 Grupos étnicos \\
\hline VII. TUPI GUARANI & 02 Grupos étnicos \\
\hline VIII. CAHUAPANA & 02 Grupos étnicos \\
\hline IX. SIN CLASIFICACIÓN & 04 Grupos étnicos \\
\hline X. PEBA YAGUA & 01 Grupo étnicos \\
\hline XI. HUITOTO & 06 Grupos étnicos \\
\hline XII. HARAKMBET & 07 Grupos étnicos \\
\hline XIII. TACANA & 01 Grupo étnico \\
\hline XIV. TUCANO & 03 Grupos étnicos \\
\hline XV. ZAPARO & 04 Grupos étnicos \\
\hline
\end{tabular}

Fuente: elaboración propia en base al mapa etnolingüístico del Perú. 


\section{ZONIFICACIÓN DE LA AMAZONÍA CUSQUEÑA}

El 53 \% de la extensión del territorio del departamento del Cusco es amazónico (ceja de selva, selva alta y selva baja), pero el $70 \%$ de la población vive en el área andina. En el área andina la lengua materna es el quechua y en la amazónica existen varias lenguas originarias, como el matsigüenka, asháninca, yine, wachipere, entre otros, y nuestro interés de publicarlo en este contexto es colaborar con el actual gobierno, que parece que se ha perdido elaborando la línea de base de las comunidades con el fin de aplicar la "Ley de Consulta".

La parte amazónica del departamento del Cusco, para fines del presente análisis, la dividimos "en cinco zonas o cuencas", que tienen características socioculturales, económicas y ecológicas diferentes.

\section{Cuadro 2}

\section{ZONIFICACIÓN DE LA SELVA CUSQUEÑA Y UBICACIÓN DE LAS ETNIAS}

\begin{tabular}{|c|c|c|c|}
\hline CUENCAS & $\begin{array}{l}\text { UBICACIÓN } \\
\text { POLÍTICA }\end{array}$ & $\begin{array}{c}\text { UBICACIÓN } \\
\text { HIDROGRÁFICA }\end{array}$ & $\begin{array}{c}\text { FAMILIAS } \\
\text { LINGÜIISTICAS Y } \\
\text { GRUPOS ÉTNICOS }\end{array}$ \\
\hline $\begin{array}{l}\text { I. ALTO URUBAMBA } \\
\text { (hasta el pongo de } \\
\text { Mainique) }\end{array}$ & $\begin{array}{l}\text { Prov. La Convención } \\
\text { (dist. Echarati y } \\
\text { Qellouno), prov. Calca } \\
\text { (distrito Lares) }\end{array}$ & $\begin{array}{l}\text { Cuenca Alta del Río } \\
\text { Urubamba }\end{array}$ & $\begin{array}{l}\text { Familia Arahuaca } \\
\text { - Etnia matsigüenka }\end{array}$ \\
\hline $\begin{array}{l}\text { II. BAJO } \\
\text { URUBAMBA } \\
\text { (Desde el pongo de } \\
\text { Mainique hasta su unión } \\
\text { con El Tambo para } \\
\text { formar el río Ucayali) }\end{array}$ & $\begin{array}{l}\text { Prov. La Convención } \\
\text { (dist. Echarati }\end{array}$ & $\begin{array}{l}\text { Cuenca Baja del río } \\
\text { Urubamba }\end{array}$ & $\begin{array}{ll}\text { A: } & \text { Familia arahuaca: } \\
\text { - Etnia matsigüenka } \\
\text { - Etnia asháninka. } \\
\text { - Etnia caquinte } \\
\text { - Etnia nanty, kirineris } \\
\text { - Yine } \\
\text { B) Familia pano } \\
\text { - Etnia nahua } \\
\end{array}$ \\
\hline III. APURÍMAC & $\begin{array}{l}\text { Prov. La Convención. } \\
\text { Dist. Pichari y Quimbiri }\end{array}$ & $\begin{array}{l}\text { Cuenca del río } \\
\text { Apurímac }\end{array}$ & $\begin{array}{l}\text { Familia arahuaca } \\
-\quad \text { Etnia matsigüenka } \\
\text { - } \quad \text { Etnia ashaninca }\end{array}$ \\
\hline IV. Alto Madre de Dios & $\begin{array}{l}\text { Prov. Paucartambo (dist. } \\
\text { Kcosñipata) }\end{array}$ & $\begin{array}{l}\text { Cuenca Alta del río } \\
\text { Madre de Dios }\end{array}$ & $\begin{array}{l}\text { A. Família harakmburut } \\
\text { - Etnia wchipere } \\
\text { B. Familia arahuaca } \\
\text { - Etnia } \\
\text { matsigüenka } \\
\end{array}$ \\
\hline $\begin{array}{l}\text { V. ARAZA o } \\
\text { QUINCE MIL }\end{array}$ & $\begin{array}{l}\text { Prov. Quispicanchi } \\
\text { Dist. Camanti }\end{array}$ & $\begin{array}{l}\text { Cuenca Media del } \\
\text { Madre de Dios. } \\
\text { Subcuenca río Inambari }\end{array}$ & $\begin{array}{c}\text { Familia harakmburut } \\
\text { - Etnia arasaire }\end{array}$ \\
\hline
\end{tabular}

Fuente: elaboración propia. 
La cuenca del río Urubamba viene a ser la más importante, porque recorre todo el Departamento de sur a norte. Esta cuenca es el mayor colector del drenaje de las aguas departamentales y al mismo tiempo la zona donde vive la gran mayoría de las comunidades nativas, y a diferencia de la cuenca del río Apurímac, se encuentra muy poco poblada debido a su configuración geográfica de cañón en su mayor parte.

\section{MAPA ETNOLINGÜÍSTICO DE LA AMAZONÍA CUSQUEÑA}

Los pueblos indígenas de la Amazonía cusqueña están, en su mayoría, organizados en comunidades nativas, y pertenecen a tres familias lingüísticas: arahuaca o arahuak, pano y harakmbut.

\subsection{FAMILIA LINGÜÍSTICA ARAHUAK}

Hasta el siglo XIX, la familia arahuak o arahuaca era conocida como "Un-Aruac". Es una de las familias lingüísticas más extensas de Sudamérica y el Caribe, y se encuentra por Guatemala, Honduras, Guayanas, Venezuela, Colombia, Ecuador, Perú, Bolivia, Brasil y Paraguay.

En el ámbito de la Amazonía del departamento del Cusco, la arahuak es la más extensa y la más importante. Pertenecen a esta familia lingüística las etnias matsigüenka, ashaninca, caquinte, nanty y yine (piro).

\section{Cuadro 3}

\section{UBICACIÓN GEOGRÁFICA DE LA FAMILIA LINGÜÍSTICA ARAHUACA}

\begin{tabular}{|c|c|c|}
\hline Departamento & Provincia & Distrito \\
\hline Cusco & Paucartambo & Kcosñipata \\
\hline Cusco & La Convención & Echarati \\
\hline Cusco & La Convención & Quimbiri \\
\hline Cusco & La Convención & Pichari \\
\hline Cusco & La Convención & Quellouno \\
\hline Cusco & Calca & Lares \\
\hline Madre de Dios & Manu & $\begin{array}{l}\text { Fitzcarrald, Madre de Dios, } \\
\text { Colorado }\end{array}$ \\
\hline Ayacucho & Huanta & Sivia \\
\hline Huánuco & Puerto Inca & Puerto Inca, Tornavisa, Yuyapichis \\
\hline Junín & Chanchamayo & Perené, Pichanaqui \\
\hline Junín & Satipo & $\begin{array}{c}\text { Coviriali, Ayilla, Mazamari, } \\
\text { Pangoa, Río Negro, Río Tambo }\end{array}$ \\
\hline
\end{tabular}




\begin{tabular}{|c|c|c|}
\hline Pasco & Oxapampa & Satipo, Puerto Bermúdez \\
\hline Ucayali & Atalaya & Raymondi, Tahuania, Yurua \\
\hline Ucayali & Coronel Portillo & Callaria, Iparia \\
\hline Ucayali & Atalaya & Sepahua \\
\hline Loreto & Ucayali & Pampa Hermosa \\
\hline
\end{tabular}

Fuente: elaboración propia (en base al Atlas de la Amazonía del Perú, EIA Lote 88, Lote 57, Inf. Cartográfica CEDIA.

Los matsigüenkas son una de las etnias más grandes del Perú, con una población cuyo $85 \%$ vive en territorio cusqueño y el otro $15 \%$ en Madre de Dios. Su territorio ancestral está ubicado entre los ríos Alto y Bajo Urubamba, Mapacho o Yavero, Apurímac, Piñi Piñi (Kcosñipata), Alto Madre de Dios y Manu.

La mayoría de la población de la etnia asháninka se encuentra entre los departamentos de Junín, Pasco y Ucayali; solo un 5 \% vive en el departamento del Cusco (río Apurímac). La etnia caquinte es un grupo pequeño, y de ella existen tres comunidades, dos de las cuales (quitepampani y taini) están en el Bajo Urubamba y la otra, Tsoroja, en el departamento de Junín. Señalan a Tsoroja como su lugar de origen y han migrado hacia el Bajo Urubamba debido a factores religiosos y últimamente por la violencia política.

Los yine o piro constituyen básicamente una etnia del departamento de Ucayali; en el departamento del Cusco contamos con dos comunidades, que son Sensa y Miaria. Solo el 10 $\%$ de su población se encuentra en el ámbito departamental, pero Miaria cumple un rol muy importante y significativo para los yine por ser considerada como la capital histórica, por lo que siempre es importante la opinión de Miaria, que junto con Sepahua y Bufeo Pozo vienen a ser las comunidades "madres" y las más grandes en población y en importancia política. La mayoría de los dirigentes de la etnia provienen de las mencionadas comunidades.

\subsection{LA FAMILIA LINGÜÍSTICA PANO}

La familia lingüística pano fue identificada por Olive A. Shell en 1965, e incluye algunas lenguas ya extintas. Se distribuye en una franja larga entre la Amazonía peruana y la selva boliviana. Desde el s. XVI existe información documentada de su presencia en el Ucayali y el Bajo Urubamba, donde desarrollaron una especie de estado Confederado Shipibo-Conibos, que tuvo una estructura débil, resistió tenazmente las labores de evangelización y a la vez se enfrentó con otros grupos panos más beligerantes, como los cashibos.

La etnia nahua vive en la zona norte de la "Reserva del Estado para poblaciones nómadas nahua, kugapakori, nanty", que se encuentra dentro del territorio del departamento del Cusco (distrito de Echarati). Su territorio ancestral está ubicado entre los ríos Serjaly, Caspajali y Misagua, en los límites departamentales de Cusco con Ucayali. La población actual se 
encuentra agrupada en la comunidad de "Santa Rosa de Serjali", que está ubicada en la margen derecha del río Serjali, donde fueron ubicados los nahuas "sobrevivientes" por la Misión Dominica, después de su "desastroso contacto" con la sociedad mayor, donde murió cerca del 60 \% de su población. Sus "chacras y su territorio de caza" se encuentran en territorio cusqueño, donde desarrollan sus actividades cotidianas.

Dentro de la Reserva del Estado para poblaciones nómadas nahua-kugapakori, también existen otras etnias que se encuentran en estado de "aislamiento voluntario", como son los nantys y kirineris, pertenecientes a la familia lingüística arahuak y otras familias que pertenecen a otros grupos humanos.

\subsection{FAMILIA LINGÜÍSTICA HARAKMBUT}

Los harakmbut viven en el suroriente de la Amazonía peruana. Su territorio tradicional se encuentra entre la margen derecha del río E'ori o Amaru Mayu (hoy conocido como Madre de Dios) y la desembocadura del Río Colorado, formando un gran trapecio con su frontera natural al oeste de los Andes, entre los departamentos de Cusco y Madre de Dios. Los principales ríos de esta región son: Queros, Huacaria, Madre de Dios, Colorado, Inambari, Yshiri, Punquiri y Malinowski.

La familia lingüística harakmbet o harakmburut es exclusiva de América del Sur. La antropóloga Patricia Lyon, en 1970, aclaró en cierto modo la confusión lingüística que existía en torno a los harakmbut. Su territorio ancestral sufrió una serie de modificaciones desde el contacto inicial en la Colonia hasta el contacto forzado que tuvieron con los caucheros, que trataron de esclavizarlos, en su desmedida ambición de explotación del caucho, llegando a producirse matanzas en su población.

En la primera década del siglo XX se produjo una gran migración de pobladores altoandinos hacia la zona, atraídos por el "boom forestal", y a partir de la década del 60 por el "boom del oro", produciéndose tráfico de personas, invasiones y muerte por transmisión de enfermedades, generándose diversas epidemias con consecuencias letales al interior de las diferentes etnias, muchas de las cuales se encuentran en "proceso de extinción", como las de los arasaires, toyeris y wachipere (huachipaires). 
Cuadro 4

UBICACIÓN GEOGRÁFICA DE LA FAMILIA LINGÜÍSTICA HARAKMBUT

\begin{tabular}{|c|c|c|}
\hline Departamento & Provincia & Distrito \\
\hline Cusco & Paucartambo & Kcosñipata \\
\hline Cusco & Quispicanchi & Camanti \\
\hline Madre de Dios & Madre de Dios & Manu \\
\hline Madre de Dios & Tambopata & Inambari \\
\hline Madre de Dios & Tahuamanu & Tahuamanu \\
\hline
\end{tabular}

Fuente: Atlas Amazónico 1997 y Diagnóstico Wachipere 2006.

El término harakmbut se utiliza como denominación tribal que les permite diferenciarse de los ese eja, matsigüenkas, amahuacas y yines o de los oakaipi (serranos) y de los ami'ko (hombres blancos). La palabra harakmbut viene de dos raíces: el verbo arak (matar) y mbut (verdad), por lo que parece aludir a su ethos guerrero. Dentro de esta familia lingüística se encuentran comprendidos los siguientes grupos étnicos:

\section{Cuadro 5}

GRUPOS ÉTNICOS DE LA FAMILIA LINGÜÍSTICA HARAKMBUT

\begin{tabular}{|c|c|c|}
\hline Familia lingüística: & GRUPOS ÉTNICOS & POBLACIÓN \\
\hline Harakmbut & Huachipaeri & 159 personas \\
\hline & Amarakaeri & 1000 “ \\
\hline & Arasaeri & 122 “ \\
\hline & Kisamberi & 37 " \\
\hline & Pukirieri & 27 \\
\hline & Sapiteri & 248 “ \\
\hline
\end{tabular}

Fuente: Atlas amazónico y Equipo Diagnóstico Huachipaire.

Para muchos investigadores ha existido una significativa caída demográfica, luego de producido el "contacto" con la sociedad mayor, y las actuales cifras representan aproximadamente el $15 \%$ de lo que fue la población. Al mismo tiempo, nos señalan que gran parte de los grupos étnicos se encuentra en proceso de recuperación, pero existen otros que se encuentran en una situación de vulnerabilidad, como las etnias huachipaire, sapiteris, kimsaberis y toyeris.

La sociedad harakmbut tiene formas de cohesión que funcionan a pesar de la segmentación en unidades culturales regionales; es así como conservan una unidad cultural que los distingue 
de otros grupos. Según Thomas Moore señala, la sociedad harakmbut es profundamente igualitaria, no existen autoridades con poder institucionalizado a las que se delegue poder formalmente. Si alguien gana respeto en una comunidad, eso no constituye un cargo heredable. Su organización social tradicional nada tiene que ver con la organización "formal" que tiene la comunidad de acuerdo a la ley de comunidades nativas y que le permite protegerse de los abusos de autoridades locales, comerciantes y otros que existen en la zona; también indica que antiguamente existía una forma de organización militar interna, basada en tres categorías que hoy prácticamente han desaparecido.

Los harakmbut se encuentran organizados en siete clanes patrilinajes localizados, siendo su norma ideal de matrimonio el intercambio de hermanas entre dos clanes, dándose dicha relación de intercambio entre los siete clanes. Según la terminología de parentesco, este se puede tipificar de parentesco Gravidio, según el cual son parientes consanguíneos los miembros del propio clan y son parientes afines teóricamente los seis clanes restantes.

El matrimonio preferencial se da con una mujer en la categoría de prima cruzada bilateral (hija de la hermana de padre / hija del hermano de la madre); adicionalmente, se puede señalar que el matrimonio se encuentra prohibido entre personas cuyas respectivas madres sean hijas de un mismo padre. El servicio matrimonial se realiza en la casa del suegro y tiene una duración de por lo menos dos años; actualmente existen casos donde se da la matrilocalidad.

La subsistencia de los harakmbut depende de la horticultura de roza y quema, la caza, la pesca y la recolección. Sus principales cultivos son los huertos de yuca, caña de azúcar, plátano, maíz y piña; en la actualidad su producción agrícola tiene por destino el autoconsumo; la producción pecuaria, pese a los esfuerzos realizados por las iglesias católica y evangélica, ha fracasado rotundamente; los harakmbut se dedican a la extracción forestal en forma individual, para lo cual son habilitados por comerciantes, pero su participación en este rubro no es muy significativa.

\section{LOS GRUPOS ÉTNICOS DEL ALTO URUBAMBA}

En el divortium aquarium de La Raya nace el río Vilconota, que recorre todo el departamento del Cusco de sur a norte, cruzando las provincias de Canchis, Quispicanchis, Paucartambo, Calca, Urubamba y La Convención, dando origen al "Valle Sagrado de los Incas". En la Convención, después de pasar por los centros poblados de Quillabamba y Echarati, en la zona de Chahuares, recibe las aguas del río Yanatile y da origen al río Alto Urubamba, que penetra hacia la Selva baja, y al atravesar el pongo de Mainique se convierte en el Bajo Urubamba. El río Yavero o Mapacho es uno de los principales tributarios del Alto Urubamba, que viene de los deshielos del nevado del Ausangate y recoge las aguas de la zona de Paucartambo. 
El ámbito del Alto Urubamba está poblado por la etnia matsigüenka y es considerado como parte de su territorio ancestral. La etnia matsigüenka es una de las más importantes del Perú y la más importante del departamento del Cusco.

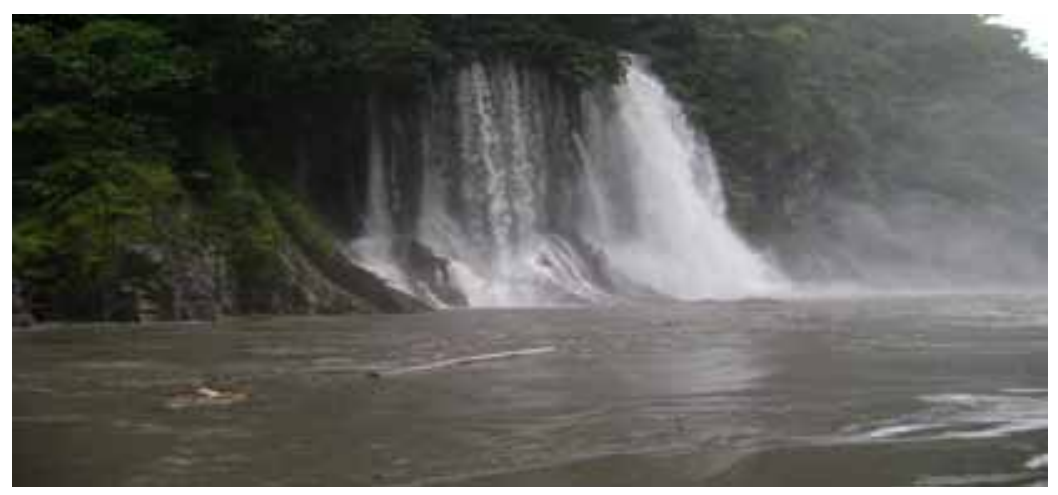

El Mainique en el río Alto Urubamba

\subsection{LA ETNIA MATSIGÜENKA}

Los matsigüenkas se autorreconocen tanto varones como mujeres como "matsigüenka", que significa "persona humana", y es conocido también con ese nombre el idioma que hablan y que les permite diferenciarse de los demás grupos humanos.

El ámbito ancestral de la etnia matsigüenka es amplio y abarca las provincias y distritos que se observan en el siguiente cuadro. Pertenecen a la cuenca del Alto Urubamba los distritos de Yanatile, en la provincia de Calca, y Echarati, en la provincia de La Convención.

Cuadro 6

ÁMBITO TERRITORIAL DE LA ETNIA MATSIGÜENKA

\begin{tabular}{|l|l|l|}
\hline \multicolumn{1}{|c|}{ DEPARTAMENTO } & \multicolumn{1}{|c|}{ PROVINCIA } & \multicolumn{1}{c|}{ DISTRITO } \\
\hline Cusco & Calca & Yanatile \\
Cusco & La Convención & Echarati \\
Cusco & La Convención & Quellouno \\
Cusco & La Convención & Quimbiri \\
Cusco & Paucartambo & Pilcopata \\
Madre De Dios & Manu & Manu \\
Madre De Dios & Manu & Fitzcarrald \\
\hline
\end{tabular}

Fuente: elaboración propia. 
Hasta la década del 50 del siglo XX han vivido en forma tradicional y han sido considerados como seminómadas. vivían en pequeños grupos de familias extendidas como actualmente siguen viviendo en el ámbito territorial del Parque Nacional del Manu, en los ríos Piñi Piñi y Manu y se dedicaban a la caza, pesca y a la agricultura de tala y quema, en ella trabajan toda la familia con una dedicación asombrosa, motivo por el cual muchos antropólogos debido al esmero y dedicación con que trabajan sus chacras las han denominado "los jardines de la selva", tradicionalmente su organización era con un jefe auto elegido, siendo un "orador" en el estilo tradicional y característico de los matsigüenkas, que les permitía infundir respeto y persuadir a las demás familias o personas ajenas del entorno familiar

Su vestido tradiciona es el cuhsma, tejido a mano en algodón en "telares muy similares" a los quechuas. Los hombres lo usan con rayas verticales y cuello en "V", las mujeres con rayas horizontales y cuello recto. Actualmente en las comunidades es usado solo por ancianas y niños. Las personas adultas y jóvenes lo usan para ciertas ceremonias o cuando salen a las ciudades para entrevistas con autoridades. Así pues, el primer gran impacto de la "civilización" ha sido sobre su vestimenta.

En las comunidades tradicionales, la esperanza de vida está alrededor de entre 50 a 55 años. Hoy esta esperanza de vida ha aumentado, especialmente en las comunidades del Alto Urubamba, a 65 años, debido a que todas las comunidades cuentan con postas sanitarias y en algunas de ellas cuentan con un centro de salud. Anteriormente, la vida era considerada como "corta y dura”, y aquí jugaba un rol muy importante el "shamán o seripigari” para conseguir ayuda de los buenos espíritus y tener un mejor destino.

Según investigadores pertenecientes al Instituto Lingüístico de Verano (ILV), institución muy ligada a la iglesia evangélica," las primeras misiones católicas y los primeros invasores europeos tuvieron poco impacto entre los matsigüienkas y más impacto tuvieron a lo largo de los siglos el intercambio con los pobladores de los Andes", jugando un papel importante el intercambio de madera, tintes, algodón, hoja de coca, plumas, hierbas medicinales con herramientas de metal.

La información histórica señala al Inca Cápac Yupanqui como el que realizó las primeras tentativas de incorporar el territorio matsigüenka al Imperio Incaico; posteriormente se establecieron "relaciones de intercambio", convirtiéndose en uno de los aliados más importantes que tuvieron los incas en el llamado Antisuyo. Cuando fue invadido el Cusco por los españoles, los incas se fueron a refugiar en un área contigua en la "cordillera de Vilcabamba”, donde resistieron aproximadamente 100 años. Después se expresa esta alianza en el levantamiento de Juan Santos Atahualpa, quien con los matsigüenkas, ashaninkas y yines en las zonas del Bajo Urubamba y la Selva Central se mantuvieron aislados de la Colonia por más de 300 años. 
Un hecho importante ocurrió en 1847, cuando se descubrió la zarzaparrilla, que fue utilizada para la fabricación de la quinina, que servía para el tratamiento de la Malaria. Esto tuvo como consecuencia el ingreso de "exploradores" a territorios de los matsigüenka para buscar esta corteza.

Posteriormente, en la época del caucho, fueron sometidos a la explotación más cruel y a la trata de personas; eran esclavizados mediante las famosas correrías y se realizó un comercio bastante grande con los niños y las mujeres, dejando miles de muertos a causa de los maltratos y epidemias.

Luego vinieron "los hacendados", que desarrollaron un sistema por el cual, los indígenas trabajaban para ellos y se les pagaba en productos, pero lo curioso del sistema era que siempre los matsigüenkas terminaban endeudados. Según manifiestan misioneros dominicos, hasta la década del 50 seguía el comercio de esclavos, y ellos intervinieron en el rescate de varias personas y por eso buscaron concentrar las familias en "pequeños centros poblados" para brindarles protección, asistencia médica y las primeras escuela. Allí se originan las actuales comunidades nativas.

En los primeros años del siglo XX, como parte del proceso de evangelización que realizaban los dominicos, se fundó la misión de Chirumbia, en 1902. Allí comenzaron a desarrollar su labor, creando posteriormente, conforme penetraban por el río Urubamba, las misiones de Koribeni, Timpia, Kirigueti y Sepahua, desarrollando actividades educativas, atención a la salud humana, acompañados con pequeños proyectos productivos en la agricultura, ganadería y pequeñas maestranzas.

La iglesia evangélica, en la década del 50, mediante un convenio que realiza con el Estado, crea el Instituto Lingüístico de Verano (ILV); desarrolla actividades similares mediante postas médicas, escuelas bilingües, aserraderos, tiendas comunales y transporte de carga en lanchas para llevar productos al mercado; uno de sus mejores aportes es el rescate de su idioma ágrafo, que ahora tiene alfabeto y escritura, y existen muchos libros en el idioma matsigüenka, destacando entre ellos la Biblia, cuentos y material didáctico de lectura para los centros educativos.

La articulación con el mercado del Alto Urubamba es más desarrollada que la de otras áreas donde viven los matsigüenkas. Se encuentran "rodeados" de asentamientos rurales producto de "la gran ola migratoria" que se produjo desde 1950 por campesinos altoandinos que abandonaban sus comunidades por la extrema pobreza en que vivían; el Alto Urubamba se presentaba como "la tierra prometida" por "la existencia de tierras sin trabajar" y los buenos precios que tenían a nivel internacional el café, el cacao, el té y el achiote. 
Se generaron importantes movimientos sociales en la década del 60, de enfrentamiento del movimiento campesino con las haciendas (pero sin participación de los matsigüenkas) que dan lugar a la Reforma Agraria y se siembra la semilla de la modernización en el agro, pero uno de los grandes errores del movimiento campesino, que tiene consecuencias actuales, ha sido la presión excesiva ejercida sobre los recursos naturales y sobre las tierras de las comunidades nativas y la ausencia de tratamiento medioambiental que más bien se ha caracterizado por la quema de miles de hectáreas del bosque amazónico a fin de habilitar tierras para el cultivo.

Las comunidades nativas que están ubicadas en el Alto Urubamba se pueden observar en el siguiente cuadro:

\section{Cuadro 7}

\section{COMPOSICIÓN ÉTNICA DEL ALTO URUBAMBA}

\begin{tabular}{|c|c|c|c|c|}
\hline $\begin{array}{l}\text { Familia } \\
\text { lingüística }\end{array}$ & $\begin{array}{l}\text { Nombre } \\
\text { conocido }\end{array}$ & $\begin{array}{l}\text { Autodeno- } \\
\text { minación }\end{array}$ & Comunidad nativa & Ubicación \\
\hline \multirow[t]{14}{*}{ Arahuak } & Machigüenga & $\begin{array}{l}\text { Matsigüen } \\
\text { ka }\end{array}$ & $\begin{array}{l}\text { 01. Comunidad Chakopishiato } \\
\text { (tiene ampliación R. Mantalo). }\end{array}$ & $\begin{array}{l}\text { Río Kumpirushiato y } \\
\text { Alto Materiato. }\end{array}$ \\
\hline & & & 03. Comunidad Corimani & $\begin{array}{l}\text { En carretera } \\
\text { Kumpiroshiato }\end{array}$ \\
\hline & & & $\begin{array}{l}\text { 04. Comunidad Estrella del Alto } \\
\text { Sangobatea }\end{array}$ & Río Tiringaveni. \\
\hline & & & 05. Comunidad Inkaare & Río Postakiato. \\
\hline & & & $\begin{array}{l}\text { 06. Comunidad San José de } \\
\text { Koribeni (ampliac en Mantalo) }\end{array}$ & $\begin{array}{l}\text { Ríos Koribeni y } \\
\text { Urubamba }\end{array}$ \\
\hline & & & 07. Comunidad Matoriato & Ríos Matoriato y Yavero. \\
\hline & & & 08. Comunidad Monte Carmelo & $\begin{array}{l}\text { Ríos Manogali } \quad y \\
\text { Urubamba }\end{array}$ \\
\hline & & & 09. Comunidad Poyentimari & $\begin{array}{ll}\text { Ríos Poyentimari y } \\
\text { Mantalo }\end{array}$ \\
\hline & & & 10. Comunidad Porenkishiari & Río Pachiri \\
\hline & & & 12. Comunidad Tipeshiari. & Río Mantalo. \\
\hline & & & 13. Comunidad Tivoriari. & $\begin{array}{l}\text { Ríos Poyentimari- } \\
\text { Kumpiroshiato } \\
\end{array}$ \\
\hline & & & 14. Comunidad Yoquiri & Ríos Yoquiri y Yavero. \\
\hline & & & 15. Comunidad Alto Picha & Río Alto Picha y Parotori. \\
\hline & & & 16. Comunidad Aendoshiari & $\begin{array}{l}\text { Ríos Talankato y } \\
\text { Sanguibeni }\end{array}$ \\
\hline
\end{tabular}

Fuente: elaboración propia para el diagnóstico socioeconómico. Región Inka, Cusco, 1997. 
Los matsigüenkas actualmente producen cacao, café y achiote para el mercado en pequeñas cantidades y mantienen sus cultivos tradicionales de pan llevar como son la yuca, la sacha papa, pituca, camote, maní, maíz y el plátano, junto a la cría de aves de corral y animales menores. La caza y la pesca siguen teniendo importancia en su economía de subsistencia; en los últimos cuatro años las comunidades que se encuentran a lo largo del tramo del gasoducto han ingresado a trabajar a las empresas contratistas percibiendo salarios que han impactado en la economía familiar en forma muy significativa.

La organización social tradicional de los matsigüenkas estaba constituida por parentelas cognáticas cuyos miembros se encuentran dispersos en diferentes asentamientos, y dividen el espacio social en dos mitades: consanguíneo y afines; en la terminología de parentesco es de tipo dravidio. De acuerdo con las reglas de exogamia, un individuo debe casarse fuera del ámbito de consanguinidad.

Esta organización ha cambiado "bruscamente" por el permanente ingreso de colonos al Alto Urubamba, convirtiendo a las comunidades en "islas mediterráneas" que han llevado a alterar sus relaciones de parentesco y de estas con el medio ambiente. Su impacto es tal que en algunas comunidades se ha perdido el idioma original y otras se han convertido en comunidades "trilingües", donde hablan compulsivamente el castellano, quechua y el matsigüenka.

\section{LOS GRUPOS ÉTNICOS DEL BAJO URUBAMBA}

La composición etnolingüística de la cuenca del Bajo Urubamba nos la señala como una zona más heterogénea por la existencia de mayor cantidad de grupos étnicos, pero bastante homogénea por el predominio de la familia arahuak (84,7 \%), que tiene un lenguaje similar que facilita su comunicación, y que en sus costumbres no tiene diferencias radicales. En esta zona existen cinco etnias pertenecientes a la familia lingüística arahuak: matsigüenkas, yine (piro), asháninka, caquinte y nanty. Los matsigüenkas vienen a ser la población más importante y numerosa de la zona $(68 \%)$.

En orden de importancia están presentes los yine (piro), que han jugado un rol significativo en la región, los asháninka y los campa caquinte; estos dos últimos grupos migraron en las últimas décadas del siglo pasado a la zona, debido a factores religiosos, a la presión migratoria de campesinos serranos, y finalmente, entre las décadas del 80 y 90, han huido de la violencia política y la muerte que generó Sendero Luminoso, el MRTA y el Ejército Peruano en los Valles del río Apurímac, Tambo y Ene. La familia etnolingüística pano está ubicada en los límites departamentales del Cusco con Ucayali, en el río Misahua.

También es importante señalar que en el Bajo Urubamba se generaron actos de violencia 
por la incursión de empresas extractivas de los recursos naturales (flora, fauna), destacando la explotación del caucho, que tuvo consecuencias "catastróficas" para muchas etnias que fueron explotadas y casi exterminadas, cambiando el mapa sociocultural de la zona por los fuertes impactos que produjo.

En las últimas décadas del siglo XX, la presencia de los extractores de madera ha generado importantes impactos que no solo han causado deterioro de su medio ambiente, donde casi han extinguido las especies maderables del cedro y la caoba, sino han realizado contactos forzados como con los nahuas, $\mathrm{y}$ al ingresar en forma indiscriminada a los diferentes bosques están limitando la reproducción de los recursos de subsistencia de las comunidades nativas y se están desarrollando actos lesivos, lo cual dará lugar después de algunos años a la desaparición de "algunas etnias" como los caquinte o los kirineris.

El siguiente cuadro muestra la composición étnica del Bajo Urubamba, donde podremos observar la existencia de una mayor diversidad sociocultural, que se ha mantenido gracias a la no existencia de una carretera en la zona:

Cuadro 8

COMPOSICIÓN ÉTNICA DEL BAJO URUBAMBA

\begin{tabular}{|c|c|c|c|c|}
\hline $\begin{array}{c}\text { Familia } \\
\text { lingüística }\end{array}$ & $\begin{array}{l}\text { Nombre } \\
\text { conocido }\end{array}$ & $\begin{array}{l}\text { Autodenomi } \\
\text { nación }\end{array}$ & Comunidad nativa & Ubicación \\
\hline Arahuak & Machigüenga & Matsigüenga & $\begin{array}{l}\text { 01. Savavantiari. } \\
\text { 02. Timpía. } \\
\text { 03. Ticumpinia(Chocoriari). } \\
\text { 04. Camisea } \\
\text { 05. Kirigueti(Carpintero). } \\
\text { 06. Nuevo Mundo(Mipaya) } \\
\text { 07. Nueva Vida (Paquiria) } \\
\text { 08. Nueva Luz } \\
\text { 09. Shivankoreni } \\
\text { 10. Segakiato } \\
\text { 11. Cashiriari } \\
\text { 12. Pto. Huallana } \\
\text { 13. Mayapo } \\
\text { 14. Camana } \\
\text { 15. Campo Verde } \\
\text { (anexo Kochiri) } \\
\text { 16. Kitepampani } \\
\text { 17. Pamencharoni } \\
\text { (anexo Kirigueti) } \\
\text { 18. Porotovango }\end{array}$ & $\begin{array}{l}\text { Río Ticumpinia } \\
\text { Río Urubamba } \\
\text { Río Urubamba } \\
\text { Río Camisea/ } \\
\text { Urub } \\
\text { Río Urubamba } \\
\text { Río Urubamba } \\
\text { Río Urubamba } \\
\text { Río Urubamba } \\
\text { Río Camisea } \\
\text { Río Camisea } \\
\text { Río Camisea } \\
\text { Río Picha } \\
\text { Río Picha } \\
\text { Río Parotori } \\
\text { Río Pagoren } \\
\text { Río Ayeni } \\
\text { Río Miyapa } \\
\text { Río Huitricaya } \\
\text { Río Potagari }\end{array}$ \\
\hline
\end{tabular}




\begin{tabular}{|l|l|l|l|l|}
\hline Arahuak & $\begin{array}{l}\text { Campa } \\
\text { Asháninka }\end{array}$ & Asháninka & $\begin{array}{l}\text { 19. Pto Rico } \\
\text { 20. Kochiri } \\
\text { 21 Tangoshiari } \\
\text { 22. Selva Verde } \\
\text { (anexo Nvo. Mundo) }\end{array}$ & $\begin{array}{l}\text { Río Miaría } \\
\text { Río Pagoreni } \\
\text { Río Tangoshiari } \\
\text { Río Tsevetari }\end{array}$ \\
\hline Arahuak & $\begin{array}{l}\text { Campa } \\
\text { Caquinte }\end{array}$ & $\begin{array}{l}\text { Caquinte } \\
\text { Poyenisati }\end{array}$ & $\begin{array}{l}\text { 23. Kitepampani. } \\
\text { 24. Taini }\end{array}$ & $\begin{array}{l}\text { Río Miyapa } \\
\text { Río tsoyeni }\end{array}$ \\
\hline Arahuak & Kugapakori & Nanti & $\begin{array}{l}\text { 25. Alto Timpía. } \\
26 . \text { Montetoni } \\
\text { 27.Marankeato. } \\
\text { 28. Sagontoari }\end{array}$ & $\begin{array}{l}\text { Río alto Timpía } \\
\text { Río Alto Camisea. } \\
\text { Río Alto Camisea } \\
\text { Río Alto Camisea }\end{array}$ \\
\hline Arahuak & Piro & Yine & $\begin{array}{l}\text { 29. Sensa } \\
\text { 30. Miaría }\end{array}$ & $\begin{array}{l}\text { Río Urubamba } \\
\text { Río Urubamba }\end{array}$ \\
\hline Pano & Yaminahua & Yori & $\begin{array}{l}\text { Santa Rosa (comunidad } \\
\text { reubicada en el distrito } \\
\text { Sepahua, pero sus chacras y } \\
\text { territorios de caza están en } \\
\text { el departamento del Cusco) }\end{array}$ & $\begin{array}{l}\text { Río Serjali } \\
\text { Río Sepahua }\end{array}$ \\
& & & &
\end{tabular}

Fuente: elaboración propia para el diagnóstico socioeconómico. Región Inka, Cusco, 1997.

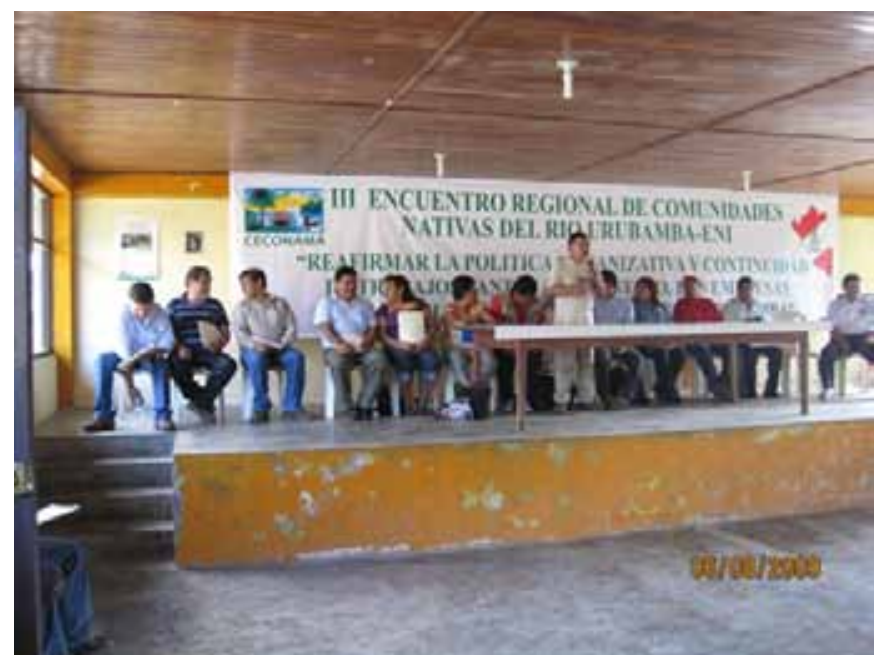

Asamblea de las comunidades del Bajo Urubamba

\subsection{LA ETNIA MATSIGÜENKA}

La llamada "época" de oro para la Amazonía por la explotación del Caucho y su impacto en la economía nacional e internacional fueron, sin embargo, las épocas más negras para las etnias amazónicas, y en particular para los matsigüenkas, que fueron perseguidos y "cazados" 
por los traficantes del caucho, para ser esclavizados y vendidos para su explotación como mano de obra.

Según relatan los misioneros dominicos, esta situación de persecución y de tráfico humano subsistió hasta la década del 50 del siglo XX, como relatan los padres dominicos que ingresaron a la zona para formar la Misión Católica del Sepahua y que son testimonio muy importante sobre el rescate de muchas familias de matsigüenkas de manos de traficantes y de cómo se formaron misiones que desarrollaban principalmente actividades de educación y de atención de la salud, que permitieron nuclear familias para brindar estos servicios y posteriormente fueron el núcleo para la formación de las actuales comunidades nativas que existen en la zona.

Su aislamiento del área del Bajo Urubamba permitió que su medio ambiente fuera muy poco disturbado y se convirtió en una zona de megabiodiversidad importante y sin alteración del hombre, dando lugar al nacimiento de "Áreas Naturales Protegidas" como el Parque Nacional Otishi, el Santuario Nacional de Megantoni, la Reserva Comunal Machigüenga y la Reserva Nacional Asháninca.

En la comunidad de Nueva Luz se encuentra el río Paquiria, en cuya parte alta viven una treintena de familias en "situación de aislamiento voluntario", que no quieren mantener relaciones con la "sociedad mayor", manteniendo relaciones con algunas familias matsigüenkas de la comunidad y se han autodenominado "kirineris", que son parte de la "Reserva Nacional de Poblaciones Nómades nahua, kugapakori, nanty”, que inicialmente fue administrada por el INDEPA, posteriormente por la Dirección General de Pueblos Originarios y Afroperuano del MIMDES, y finalmente hoy se encuentra dentro de la estructura del Ministerio de Cultura. Por los múltiples pasos dados en la protección de esta área, da la impresión que para el Estado Peruano viene a ser una "papa caliente" que no sabe cómo administrar y proteger. Todo se debe a que en su área existen los pozos de gas que explota la Plus Petrol, y pareciera que esta ejerce una presión sobre el Estado, entrando en conflicto un área remota donde se han refugiado grupos de poblaciones nómades en aislamiento o en contacto inicial con los intereses petroleros del consorcio que lidera Plus Petro. Hasta la fecha solo se ha puesto una garita de control en el río Paquiria que les permite controlar el ingreso de madereros o aventureros, respetando su decisión de vivir en asilamiento.

Al encontrarse en esta zona los lotes de exploración y explotación de importantes yacimientos de gas, las comunidades que directamente están siendo impactadas por sus actividades han producido dos dinámicas socioeconómicas, al punto que cada vez parece que se distancian más.

Una dinámica que se articula con la economía moderna tiene como base a las comunidades que están ubicadas en el río Bajo Urubamba, donde la mayoría de la población es contratada por 
las empresas para las actividades económicas que desarrollan, impactando en sus economías, costumbres, vivienda y otros, produciendo cambios rápidos en sus patrones culturales. Otra dinámica promueve una economía tradicional con sus antiguas comunidades ubicadas en la zona de los ríos secundarios y que mantienen su cultura con pocas alteraciones. En esta zona existen 5 asociaciones de colonos que tratan de vivir pacíficamente con las comunidades de la zona.

\subsection{LA ETNIA YINE (PIRO)}

Los yine o piro tuvieron sus primeros contactos con los españoles a mediados del siglo XVII, con los misioneros franciscanos y jesuitas que llegaron en sus exploraciones evangélicas hacia las zonas del río Tambo y el Bajo Urubamba. Los padres Herrera y Biedma han dejado valiosos escritos sobre sus recorridos y el padre jesuita Richter redactó un catecismo en su idioma.

A fines del siglo XVIII, los yines extendieron su territorio hasta los ríos Tambo, Ucayali y Cujar. En 1795, se fundó la primera misión piro y en 1809 la segunda misión. Después de las guerras de la Independencia y el cierre de la sede misional de Santa Rosa de Ocopa, a inicios del siglo XIX, los misioneros franciscanos se retiraron por un tiempo prolongado de la zona.

A inicios del siglo XX, los yine participaron envueltos en la violencia desatada por los patrones caucheros, siendo reclutados como mano de obra para la extracción del caucho y como cazadores de esclavos. Los patrones del caucho se llevaron a un sector importante de este grupo fuera de su territorio tradicional, el Bajo Urubamba, a otras zonas del río Ucayali y a los ríos Manu y las Piedras, en el Departamento de Madre de Dios. También fueron trasladados a la cuenca del río Purús y Caspah, en el Estado de Acre de la República del Brasil.

Después de ese período negro del caucho, que les trajo mucho sufrimiento, llegaron, por la décadas del 40 al 60 del siglo XX, las haciendas y los terratenientes, que optaron por la modalidad de venderles a crédito las mercaderías a cambio de su mano de obra, pero el pago que recibían era tan bajo que era imposible pagar sus deudas. Este sistema de patrón-peón los explotó mucho.

Hoy viven las comunidades yine dispersas en un amplio territorio y por la ocupación territorial se autorreconocen en tres subgrupos: los yine yami en la cuenca del Bajo Urubamba, lugar originario de la etnia; los yine manuhajene, ubicados en las cuencas de los ríos Alto Madre de Dios y las Piedras; y los yine manchineri o manetineri, que están en el Estado de Acre, en el vecino país de Brasil, en la cuenca del río Purús (entre la boca del río Iaca y del Curinaha) y en los ríos Maloca y Caspah. Existe un importante grupo que vive entre el Manu y las cabeceras del río los Amigos, denominados "mashco piros", que viven en aislamiento voluntario. 
Los yine peruanos viven en los distritos, provincias y departamentos mostrados en el siguiente cuadro:

\section{Cuadro 9}

Distribución espacial de los yines

\begin{tabular}{|l|l|l|}
\hline DEPARTAMENTO & PROVINCIA & DISTRITO \\
\hline Cusco & La Convención & Echarati \\
\hline Loreto & Ucayali & Pampa Hermosa \\
\hline Madre de Dios & Manu & Madre de Dios \\
\hline Madre de Dios & Tahuamanu & Iñapari \\
\hline Ucayali & Atalaya & Raymondi \\
\hline Ucayali & Atalaya & Sepahua \\
\hline
\end{tabular}

Fuente: elaboración propia.

Los yine en forma tradicional han vivido como seminómadas y sus casas tenían la característica de no tener paredes. Tradicionalmente, el jefe de la comunidad era considerado como un guía y no como un dictador. Este grupo ha estado muy marcado por el rol importante que realizan las mujeres en las actividades de la familia, el clan, la etnia y a nivel distrital o provincial.

La vestimenta tradicional de los hombres era la chusma tipo túnica, tejida en algodón blanco y pintada con diseños geométricos muy vistosos. Las mujeres usaban faldas tubulares que se envolvían a la cintura. Posteriormente, con la llegada de las telas al Bajo Urubamba, cosían blusas y vestidos en colores vivos. Hoy la vestimenta es la que usa cualquier poblador amazónico a la moda.

Según el Padre Álvarez Lobo, los yine están organizados en seis clanes matrilineales. La terminología de parentesco es de tipo iroquesa, que subraya la diferencia entre primos paralelos y cruzados. Álvarez Lobo, Zarzar, Mora y Matteson manifiestan que los yines tienen un modelo de matrimonio referencial con la prima cruzada, pero otro grupo de antropólogos manifiesta que en la elección de la pareja prima el criterio de "personas lejanas socialmente".

La residencia postmatrimonial en la mayoría de los casos es matrilocal; la pareja, luego de un tiempo, puede construir su propia casa, pero no debe ser lejos de la del suegro. No se da servicio por la novia, pero se espera que el yerno ayude a sus suegros. La relación del yerno con los suegros es de respeto y muy jovial. Los yines han desarrollado formas de parentesco espiritual del tipo compadrazgo. Esta relación se establece a través del corte del cordón umbilical del recién nacido por el compadre. 
La horticultura es la actividad más importante para la subsistencia de las familias; producen yuca, plátano, arroz, maíz, camote, sachapapa, calabaza y frejol. La caza y la pesca son esenciales para su subsistencia. Existen grupos de familias en Miaria que pescan y abastecen al centro poblado de Sepahua. La recolección de frutos como el aguaje, el ungurahui y el pijuayo es importante. Los yines venden a los regatones o directamente en los centros poblados de Atalaya y Sepahua, maíz duro, frijol, arroz y harina de yuca o "farinha". La extracción de la madera se realiza también con fines comerciales y se vende en Sepahua.

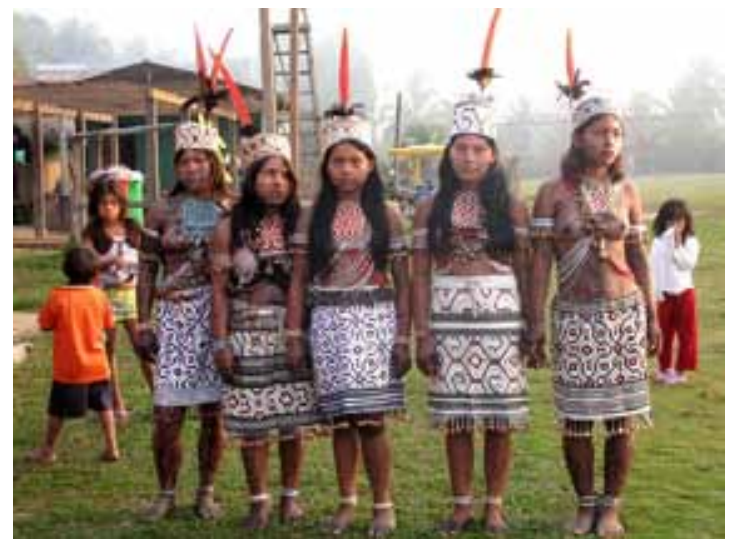

Yines del Bajo Urubamba

\subsection{LA ETNIA NAHUA}

Bajo la denominación nahua se incluye también a los subgrupos chitonahua, morunahua, chandinahua y maxonahua o cujareño, que viven en aislamiento. Las familias que viven entre los ríos Serjali y Misagua se autoreconocen como "yora", pero los otros grupos de las familias pano les dieron el nombre de "nahua" ("no nosotros"), nombre con el que se les ha identificado. Regionalmente han recibido otros nombres como sharas y parquenahuas porque una parte de su territorio está en el Parque Nacional del Manu. El grupo de yaminahuas que vive en Sepahua se dirige a ellos con el término de "yobashta". Su población estimada es de 450 .

Los nahuas o yuraa, que habitan actualmente el curso medio alto del río Mishagua, constituyen el grupo de más reciente integración a la sociedad nacional. Establecieron contacto definitivo en 1984 mediante "madereros". Se sabía de su existencia desde mediados del siglo pasado debido a que bajaban desde las cabeceras del Mishagua y su afluente el Serjali hasta su desembocadura en el Bajo Urubamba, donde se producían enfrentamientos con los nativos asentados en la misión dominica de Sepahua. 
En 1974 se verificaron enfrentamientos entre nahuas y madereros provenientes de Pucallpa (Atalaya), donde resultaron varios madereros heridos, y posteriormente regresaron los madereros acompañados de un grupo de indígenas de otros grupos, para contraatacar a los nahuas. También se tiene registrado otro conflicto en 1981 con los madereros, con un saldo de dos heridos.

En 1984, se registró un enfrentamiento con marinos que se encontraban trabajando un proyecto de interconexión fluvial que uniría las cuencas de los ríos Urubamba con el Madre de Dios, coincidiendo con la visita que realizaba el Presidente Fernando Belaúnde a la zona.

El ILV nos ha proporcionado esta información recogida de los nahua para explicar su contacto con la sociedad mayor: "Dicen que se habían asustado por el padre grande en el cielo pensando que era un espíritu”. Refiriéndose a una avioneta de exploración de una Empresa Petrolera: "En las noches habían escuchado fuertes ruidos y pensaron que eran ruidos producidos por los espíritus que luchaban en la oscuridad". Refiriéndose a las explosiones que se realizan durante las operaciones de sísmica en las exploraciones en búsqueda del petróleo: "Por eso prefirieron esconderse en lo más recóndito de la selva, evitando el contacto con otras personas".

Por eso atacaban a los madereros y colonos que se acercaban a su territorio. Después de muchos enfrentamientos, algunos de los cuales hemos señalado líneas arriba, el año 1984, un grupo de madereros capturó a un grupo de nahuas - a uno de ellos le dieron el sobrenombre de "Raya" (que es un pez amazónico) — y los llevaron a vivir a Sepahua. Meses después, "Raya" regresó a su comunidad y les habló de su experiencia e influyó para que los nahuas decidieran salir. Ellos habían dicho antes de salir: "Queremos vivir en paz", y salieron y establecieron contacto con el mundo exterior.

$\mathrm{Al}$ realizar este contacto, las autoridades de la zona no tomaron las precauciones sanitarias adecuadas. Los nahuas se infectaron con el virus de la gripe y en las seis semanas siguientes murieron aproximadamente unas 50 personas. Durante los siguientes cinco años las epidemias siguieron causando mucha mortandad, y para su atención se los ubicó en tres campamentos. En los siguientes tres años no nació un solo niño y las epidemias los extenuaron tanto que no tenían energía para trabajar en sus chacras.

Este contacto fue una tragedia para la etnia, que perdió a las dos terceras partes de su población aproximadamente, lo que nos debe llevar a sacar enseñanzas para no repetir esta tragedia. Hoy ellos se han reagrupado y han fundado un centro poblado y están solicitando el reconocimiento de su comunidad, a la que han llamado Santa Rosa de Serjali, que ya cuenta con una escuela, y en la que cada familia tiene sus chacras cultivadas. 


\subsection{LOS NANTI}

Desde el siglo XVI, con la llegada de los españoles, se han propagado enfermedades hasta entonces desconocidas en América, y contra las cuales se carecía de anticuerpos. Este ha sido uno de los factores que ha incidido para la desaparición de muchos grupos étnicos indígenas. Desde 1950, aproximadamente, siete familias lingüísticas han desaparecido, y otros 18 grupos y subgrupos pertenecientes a cinco familias lingüísticas se encuentran en peligro de extinción.

Existen varios grupos que se encuentran en peligro de extinción en un plazo bastante corto (entre una y dos generaciones). Entre los que se encuentran en esta situación están los chamicuro, ocaina, huachipaire, sapiteri y pukieri. Algunos grupos que se encuentran en este proceso están en "situación de aislamiento voluntario", como los mashco-piros, chitonahua, maxonahua, morunahua y nantis.

Esta pérdida reciente de diversidad cultural por la que atraviesa la Amazonía peruana, en particular algunos grupos de nuestro departamento, se debe al estado de extrema vulnerabilidad en que se encuentran actualmente diversos grupos.

Se sabe que existen contactos esporádicos, aunque cada vez más frecuentes, entre los kugapakoris y los machigüenka, así como entre los mashco-piro y los piros. Se puede suponer, además, que existe algún tipo de contacto entre los diversos grupos nahua. Esta situación ha llevado a plantear la necesidad de generar áreas reservadas que permitan la supervivencia de los grupos en aislamiento, como es el caso en el Alto Timpia y el Alto Camisea para la población nanta en la Reserva del Estado, en favor de los grupos nómadas nahua- kugapakori del departamento del Cusco.

Existe información que se está produciendo una situación transitoria desde hace aproximadamente unos 15 a 20 años, como es el caso de los nahua y de los nantis, con la iniciación de movimientos migratorios que indican que están saliendo de las cabeceras y quebradas hacia su establecimiento en los cursos medios y altos de los ríos Camisea y Alto Timpi.

Este proceso se ha caracterizado por la formación de núcleos de dichas poblaciones y su sedentarización. Por parte de los nahuas, se está produciendo en la comunidad Santa Rosa de Serjali en el departamento de Ucayali, en la frontera con el Cusco, y de los nantis de las cabeceras del río Timpia, en el sector denominado Gavilán y en los sectores del Alto Camisea ( Montetoni, Malanquiato y Sagontoari).

En las cabeceras del río Camisea se inició este proceso de migración y formación de núcleos en el sector de Montetoni con unas 45 familias, llegando a contar con un centro educativo. Posteriormente, se produjo la violación de nueve niñas por parte del profesor, y 
por conflictos internos, 23 familias se fueron de Montetoni y formaron Malanquiato, a una hora más abajo de Montetoni. Hoy otras 15 familias han formado aguas más abajo, en el río Camisea, Sagontoari, otro lugar donde se está produciendo el proceso de sedentarización.

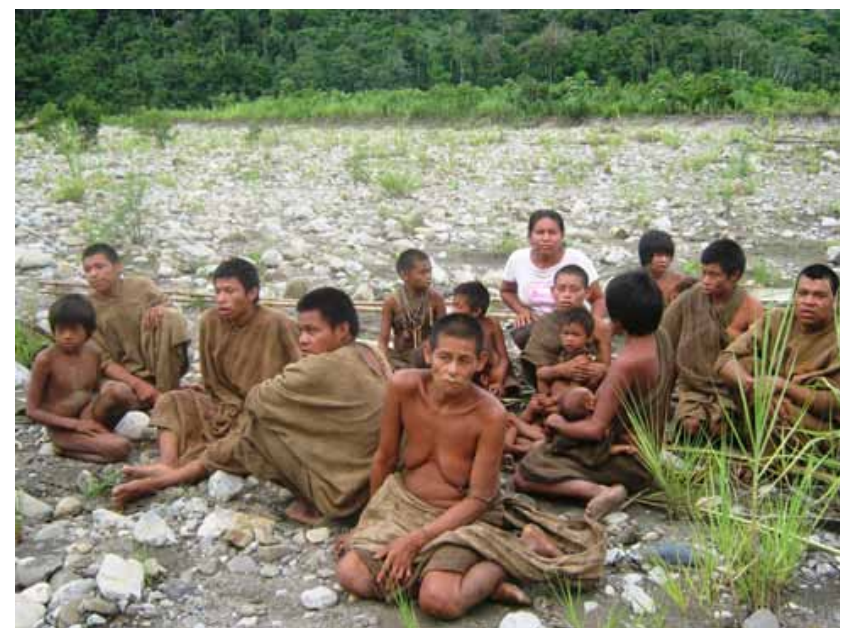

Etnia Nanty

\subsection{ETNIA CAQUINTE}

Los caquinte son parte de los campas. Caquinte significa "gente", y son aproximadamente unas 300 personas que viven entre los ríos Poveni (tributario del río Tambo) y Agüen, que es tributario del río Urubamba. Según el ILV, su idioma es el arahuaco-maipuran, siendo” muchas palabras claramente diferentes de las otras lenguas de la familia arahuack". Debido a que han vivido separados, han experimentado la influencia de las demás lenguas vecinas. Así mismo, los lingüistas del ILV mencionan que "hay bastante diversidad en el vocabulario de los diferentes grupos familiares, pero que pueden entenderse entre ellos”.

En su historia oral cuentan "que son descendientes de un hombre que vino de las grandes extensiones de agua y que se casó con una mujer Asháninka...”. En el pasado vivían en pequeños grupos familiares con una estructura familiar fuerte. A lo largo de la historia han querido formar una sola comunidad y vivir juntos pero a causa de peleas entre los clanes y en un caso por una peste que diezmó a su población, decidieron separase. En dos casos fueron atacados por sus vecinos, lo que los obligó a separarse nuevamente y se dividieron en tres grupos.

Actualmente viven en tres comunidades: Tsoroja, Quitepampani y Taini. Señalan a Tsoroja, que está en el departamento de Junín, como su lugar de origen y la que tiene un mayor número de familias (175 familias). 
Un grupo salió hacia el río Urubamba por discrepancias entre los clanes que hemos mencionado, y también por factores de presión. Se dirigíó hacia las tierras de los colonos y vivió durante dos décadas en una comunidad matsigüenka del río Urubamba. Luego, en 1975 conformaron la comunidad de Quitepampani, para posteriormente formar la comunidad de Taini, que actualmente se encuentra dentro de la reserva comunal machigüenga.

Antes se vestían con una "tela rústica de corteza batida" que usaban de noche para abrigarse. Posteriormente, por influencia de las comunidades vecinas comenzaron a usar el cushma de algodón tejido a mano. La poligamia sigue siendo una práctica común y los varones tienen como esposa generalmente a dos hermanas, y el matrimonio se realiza entre primos cruzados.

El territorio que viven, en el caso de Quitepampani, está en los límites de la reserva comunal matsigüenka, y en el caso de la comunidad Taini está dentro de la reserva, que es rica en animales de caza y abundante en peces. Su suelo es también muy productivo.

No están acostumbrados a vivir bajo una estructura de autoridad ni a trabajar juntos en un número significativo de familias. Hace unos 15 años atrás encontramos a Ugarte Salazar como jefe de la comunidad quitepampani, y hoy se ha producido un desplazamiento importante del mencionado clan hacia la comunidad taini, llevándose a casi el $50 \%$ de la población de Quitepampani.

\subsection{LOS ASHÁNINKAS DEL BAJO URUBAMBA}

Los asháninkas tienen su origen entre los ríos Tambo y Ene, de donde uno de los grupos migró en la década del 70 del siglo pasado por la fuerte presión que existió en la zona por migración andina y por motivaciones religiosas. Lideró esta movilización el legendario Morán Zumaeta, instalándose primero en Bufeo Pozo y después en Miaria, para posteriormente constituir la comunidad de Puerto Rico, uniéndose más adelante otro grupo por motivos de la violencia política y del narcotráfico. Fue la única comunidad que tuvo las rondas en el Bajo Urubamba, y caminaban armados de fusiles proporcionados por el Ejército.

Al final de la década pasada, se realizó toda una epopeya que realizaron los padres franciscanos, que trasladaron en avionetas a cientos de asháninkas del río Tambo hacia el Urubamba para salvarles las vidas de un ataque de Sendero Luminoso, y los instalaron en las comunidades de Kochiri y Tangoshiari. Actualmente, una parte de estas familias se encuentra de regreso hacia sus zonas de origen. 


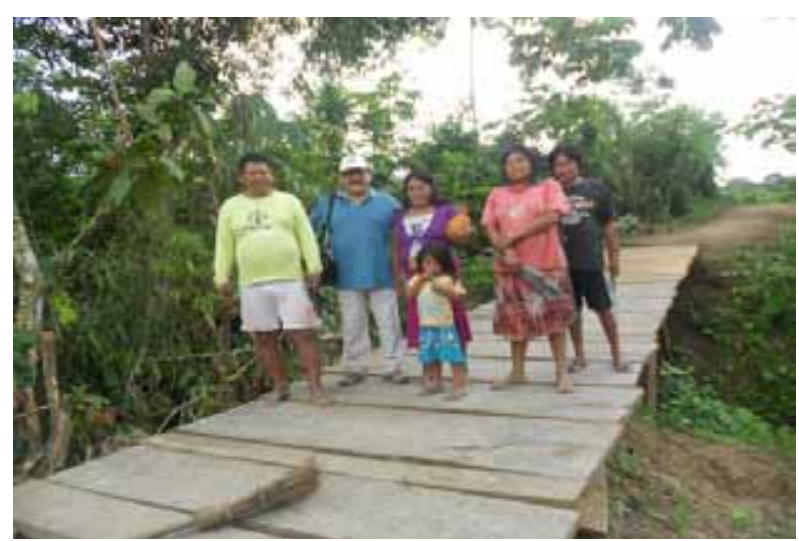

Ashánincas de la comunidad de Puerto Rico

\section{LOS GRUPOS ÉTNICOS DEL RÍO APURÍMAC}

La cuenca del río Apurímac nace a 5400 m.s.n.m. (Arequipa), y este punto es considerado como la naciente del río Amazonas Después de cruzar el sector occidental del departamento de Cusco, se convierte en el límite departamental con el departamento de Apurímac; en su recorrido recoge las aguas del río Pampas y en su confluencia con el río Mantaro forma el río Ene y posteriormente el río Tambo; la unión del Tambo con el Bajo Urubamba en Atalaya da origen al río Ucayali.

La cuenca del Apurímac y el Vilcanota se hallan separadas por la cordillera del Vilcabamba, la cual en su parte más elevada forma el círculo glaciar del Salkantay, y es considerada como una de las reservas acuíferas más importantes de la Región.

\section{Cuadro 10}

\section{COMPOSICIÓN ÉTNICA DE LA CUENCA DEL RÍO APURÍMAC}

\begin{tabular}{|c|c|c|c|c|}
\hline $\begin{array}{c}\text { Familia } \\
\text { lingüística }\end{array}$ & $\begin{array}{l}\text { Nombre } \\
\text { conocido }\end{array}$ & $\begin{array}{l}\text { Autodeno- } \\
\text { minación }\end{array}$ & Comunidad nativa & Ubicación \\
\hline Arahuak & Machigüenga & Matsigüenga & $\begin{array}{l}\text { 1. Compirushiato } \\
\text { 2. Huayanay } \\
\text { 3. Maketi } \\
\text { 4. Manitinkiari } \\
\text { 5. Mazokiato } \\
\text { 6. Shirompiari }\end{array}$ & $\begin{array}{l}\text { R. Kumpirushiato } \\
\text { R.Kitemotenkiari } \\
\text { R. Otari } \\
\text { R. Apurímac } \\
\text { R. Kitemotenkiari }\end{array}$ \\
\hline
\end{tabular}




\begin{tabular}{|l|l|l|l|l|}
\hline Arahuak & Campa & Asháninka & 7. Tsegontini & R.Pichari \\
& Asháninka & 8. Marontoari & R.Pichari \\
& & 9. Timpiñari & R. Quempiri \\
& & 10. Shinongari & R. Ene \\
& & 11. Monkirenshi & R.Pichari \\
& & 12. Sankirosi & R. Picha \\
& & 13. Sampantuari & R. Ene \\
& & 14. Otari & R. Pichari \\
& & 15. Manitinkiari & R. Apurímac \\
& & 16. Tivoriari & \\
\hline
\end{tabular}

Fuente: elaboración propia en base a mapa CEDIA y plan maestro PN Otishi.

La zona del río Apurímac, limítrofe entre Cusco, Apurímac, Ayacucho y Huancayo, más conocida como el VRAE, se ha convertido en productora de cocaína, y la violencia por este ilícito negocio es cotidiana, llevándose la peor parte las comunidades nativas.

En esta zona, como hemos visto en el cuadro, la mayor parte de las comunidades pertenece a la etnia asháninka; los matsigüenkas tienen pocas comunidades en el área.

\subsection{LOS ASHÁNINKA}

Constituyen una de las etnias más numerosas e importantes que existen en la Amazonia peruana y están ubicados principalmente en la selva central del Perú, como se puede apreciar en el siguiente cuadro. Existe en Brasil una población menor a los mil habitantes, debido a la acción de los caucheros, y en el departamento del Cusco se encuentran en los distritos de Pichari, Quimbiri, y un pequeño grupo en Echarati (Bajo Urubamba).

\section{Cuadro 11}

ÁMBITO TERRITORIAL DE LOS ASHÁNINKAS

\begin{tabular}{|l|l|l|}
\hline Departamento & Provincia & Distrito \\
\hline Ayacucho & Huanta & Sivia \\
\hline Cusco & La Convención & Echarati \\
\hline Cusco & La Convención & Quimbiri \\
\hline Huánuco & Puerto Inca & Puerto Inca, Tornavista, Yuyapichis \\
\hline Junín & Chanchamayo & Perené y Pichanaqui \\
\hline Junín & Satipo & $\begin{array}{l}\text { Coviriali, Ayilla, Mazamari, Pangoa, Rpio } \\
\text { Negro, río Tambo }\end{array}$ \\
\hline Pasco & Oxapampa & Satipo, Pto. Bermúdez \\
\hline Ucayali & Atalaya & Raymondi, Tahuania, Yurúa \\
\hline Ucayali & Coronel Portillo & Callaria \\
\hline Ucayali & Coronel Portillo & Iparia \\
\hline
\end{tabular}

Fuente: Atlas Amazónico, cartografía CEDIA, PEET, plan maestro Otishi. 
La información del censo de 1993 nos indica la existencia de 52461 personas, lo cual representa el 21,89 \% del total de la población indígena del Perú, constituyéndose en el más importante de los grupos indígenas. Están representados por 229 habitantes caquintes, 44 436 asháninkas de los ríos Apurímac, Ene, Tambo y Pichis, y 7796 asháninkas de las regiones del Alto Perené, Bajo Urubamba y Gran Pajonal. Esta información es recogida por el Atlas de la Amazonia Peruana, indicando que han existido importantes omisiones en las cuencas de los ríos Ene y Tambo, cuya área no pudo ser adecuadamente censada por la violencia política existente en la zona.

Anteriormente se les conoció con varios nombres, como andes, atis, chunchos, chascosos, kampas, cambas, tampas, thampas, komparias, kuruparias y campitis; los asháninkas han sido tradicionalmente más conocidos como campas. Hasta hace poco tiempo fueron considerados como grupos diferentes, debido a las diferencias dialectales, pero el tipo de intercambio matrimonial y de bienes entre los grupos residenciales de las diversas zonas ha permitido afirmar que se trata de una sola sociedad. El eje del sistema de intercambio, que genera la cohesión de dicha sociedad, es el intercambio de la sal extraída del "Cerro de la Sal", que fue magistralmente descrito por Stefano Varesse.

En 1635, los asháninkas comenzaron a ser evangelizados por dominicos y franciscanos, quienes fundaron una misión para los campas y amueshas cerca de La Merced, buscando controlar el Cerro de la Sal, para así tener bajo su dominio el intercambio de bienes entre las etnias de la Selva Central y ejercer su poder sobre estas. Hacia 1640, los franciscanos tenían siete centros en dicha zona, que posteriormente fueron destruidos por una rebelión. En 1671, los franciscanos restablecieron las misiones cerca del Cerro de la Sal y fundaron otras a lo largo del río Perené. Sin embargo, en 1674, se produjo un levantamiento dirigido por Fernando Torote, jefe asháninka instigado al parecer por los yines, que temían la interferencia de los franciscanos en el intercambio de sal entre ellos y los asháninkas.

En 1709, el padre Francisco de San Joseph logró avances importantes en la evangelización, llegando a tener 38 misiones; sin embargo, el gran levantamiento del líder indígena Juan Santos Atahualpa cerró la zona a cualquier actividad de ese tipo. En 1869, la resistencia armada de los asháninkas se vio quebrada en el valle de Chanchamayo, fundándose en ese año la ciudad de La Merced. En 1889, a la Peruvian Corporation, empresa de capitales ingleses, le fueron concedidas medio millón de hectáreas en los ríos Perené y Ene, iniciándose con esta concesión en la Selva Central la penetración colonizadora. Con el inicio del "boom" del caucho se instauró el comercio de esclavos campas, especialmente de mujeres y niños.

En 1965, los asháninkas, en particular los del Gran Pajonal y Satipo, se vieron envueltos en la violencia generada por los enfrentamientos entre las guerrillas del Movimiento de 
Izquierda Revolucionaria (MIR) y el ejército peruano, violencia que se repitió entre 1986 y 1996, con las violentas incursiones desarrolladas por los grupos de Sendero Luminoso y Movimiento Revolucionario Túpac Amaru, así como por las acciones desarrolladas por las fuerzas antisubversivas para controlar estos movimientos.

Los asháninkas presentan una regla de descendencia de tipo bilateral según la cual reconocen como cualitativamente iguales las relaciones del lado del padre como del lado de la madre; el grupo está constituido por todas las personas con las que un individuo establece un vínculo genealógico, por la combinación de las redes de parientes del padre y de la madre del individuo. La terminología de parentesco corresponde al tipo dravidio, que se caracteriza principalmente por separar a los parientes en dos grandes categorías: consanguíneos y afines; el matrimonio preferencial es con la prima cruzada, hija del hermano de la madre/hija de la hermana del padre. Sin embargo, en la actualidad la esposa es la prima cruzada real solo en un porcentaje mínimo de los casos registrados.

La agricultura es la principal actividad económica, siendo los principales cultivos la yuca, el plátano, el maíz, el maní, la sachapapa, la pituca, el camote, el arroz, el frijol, los cítricos, la caña de azúcar, las piñas y los frutales. La caza es también una actividad económica importante. La pesca se realiza con frecuencia, tanto en su modalidad individual como colectiva.

La agricultura comercial ha logrado un gran desarrollo en este grupo, especialmente en las comunidades localizadas en los valles de los ríos Perené y Satipo, dedicadas al cultivo del café y el achiote. La ganadería, impulsada por misioneros evangélicos y el ILV ha tenido aceptación por algunas familias.

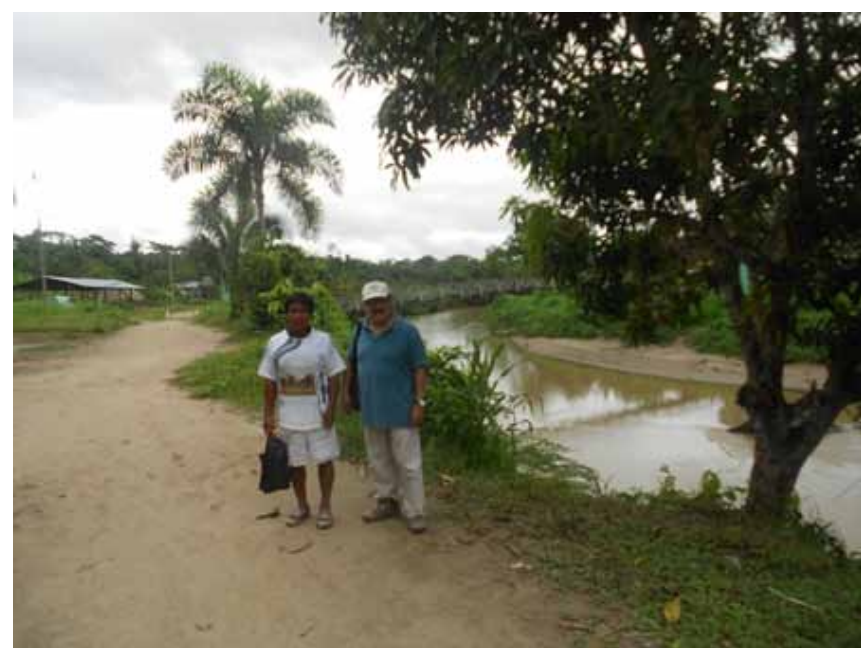

Ashánincas del río Bajo Urubamba 


\section{LOS GRUPOS ÉTNICOS DEL RÍO ALTO MADRE DE DIOS}

Los ríos que se generan en la cordillera oriental discurren en dirección sureste y este, dando origen a un centenar de pequeños y medianos ríos y riachuelos que vierten sus aguas a los cuatro principales ríos de la zona: Pilcopata, Queros, Tono y Piñi Piñi; dan origen a microcuencas de recorridos largos, torrentosos y de régimen irregular, sufriendo altas variaciones por efectos de las precipitaciones pluviales y produciendo las mayores crecientes entre los meses de noviembre a marzo.

Los ríos Pilcopata, Tono, Queros y Piñi Piñi se unen en una meseta, formando un delta cerca del centro poblado de Pilcopata, y dan origen al río Madre de Dios, que inicia un largo recorrido hacia el río Amazonas, cruzando territorio boliviano y brasileño, conformando los ríos Beni y Madeira para posteriormente para unirse al Amazonas.

El distrito de Kcosñipata está ubicado en la provincia de Paucartambo, departamento del Cusco; los pobladores de la Región conocen a la cuenca del río Pilcopata, como el valle de Kcosñipata, que ha sido territorio ancestral de los huachipaeris (ríos Queros y Pilcopata), y de la etnia matsigüenga (río Piñi Piñi).

Con el Imperio Inca intercambiaron productos y no fueron sometidos a su dominio; se generaron conflictos armados cuando quisieron ocupar su territorio. Similar actitud tuvieron con las expediciones coloniales, y en la República contra los caucheros y extractores de recursos naturales y buscadores del Paititi.

Una parte importante de las cuencas del río Tono y Piñi Piñi está dentro del Parque Nacional del Manu (PNM), y todo el Valle del Pilcopata es parte de la Reserva de Biosfera del Manu; existen poblaciones indígenas (matsigüenkas) en situación de contacto inicial, ubicadas en el río Piñi Piñi, casi todas dentro del Parque Nacional del Manu. Son zonas de difícil acceso geográfico y se encuentran en una situación de alta vulnerabilidad frente a las amenazas externas, expresadas a partir de las visitas de diversas expediciones realizadas en busca de la "mítica ciudadela del Paititi", casi todas ellas clandestinas y efectuadas sin tomar en consideración los efectos perjudiciales como la transmisión de virus y bacterias frente a las que dichas poblaciones no tienen anticuerpos, desatándose así epidemias que han terminado con la muerte de muchos indígenas (gripe y neumonía). 
Cuadro 12

COMPOSICIÓN ÉTNICA DEL ALTO MADRE DE DIOS

\begin{tabular}{|l|l|l|l|l|}
\hline $\begin{array}{c}\text { Familia } \\
\text { lingüística }\end{array}$ & \multicolumn{1}{|c|}{ Etnia } & $\begin{array}{c}\text { Autodeno- } \\
\text { minación }\end{array}$ & Comunidad nativa & \multicolumn{1}{c|}{ Ubicación } \\
\hline Harakmbut & Huachipaeri & Huachipaeri & $\begin{array}{l}\text { - Santa Rosa de } \\
\text { Huacaria. } \\
- \text { Queros }\end{array}$ & $\begin{array}{l}\text { Río Huacharía } \\
\text { Río Queros }\end{array}$ \\
\hline Arahuak & Matsigüenga & Matsiguenga & $\begin{array}{l}- \text { Del río Amalia } \\
- \text { Del río Maestron } \\
-\end{array}$ & Rel río Piñi Piñi \\
\hline
\end{tabular}

Fuente: Elaboración propia para el Diagnostico Sociocultural de la etnia Huachipaeri.

\subsection{LA ETNIA WACHIPERE (HUACHIPAERI)}

La etnia huachipaeri es parte de la familia lingüística de los harakmbut y está conformada actualmente por dos comunidades nativas: Queros y Santa Rosa de Huacaria, ambas ubicadas en el distrito de Kcosñipata. Existe un grupo importante de familias en el centro poblado de Shintuya, provincia del Manu integrado a la étnia amarakaeri y a la comunidad de Shintuya, donde funciona la misión católica de los padres dominicos.

Se autodefinen como "wachiperi", palabra que tiene dos significados: "hombres que hacen puentes de palos" y "hombres que viven bajo el puente"; se consideran descendientes del Wanamey, árbol mítico del cual se originó toda vida en este mundo. Su visión se basa en que todos somos iguales, las plantas, los animales y el hombre; al mismo tiempo, como parte de la madre naturaleza, poseemos un espíritu que armoniza nuestra relación con ella.

La información arqueológica es casi inexistente debido a los pocos estudios que se han realizado en la zona, quedando como mudo testigo de antiguos tiempos. En la comunidad de Queros, los petroglifos conocidos como "Jinkiori” y los restos incas en la cuenca del Piñi Piñi, que están siendo "huaqueados" por los buscadores del Paititi y otros aventureros, sin que ninguna Institución del Estado realice alguna actividad para impedirlo.

No cabe la menor duda de que la presencia de los incas fue muy importante y se refleja en restos de caminos, vasijas, muros, andenerías y ciudadelas, cuyas verdaderas dimensiones no conocemos por estar cubiertas de vegetación, pero sí su presencia señala que hubo un intercambio de productos locales con la producción andina muy significativo. Cronistas como Garcilaso y Huamán Poma de Ayala indican que los incas tenían desplazadas hacia la zona poblaciones que se dedicaban al cultivo de la coca, que era un producto que tenía un valor muy importante para la sociedad incaica, debido no solo a sus propiedades curativas o alimenticias, sino por el hecho de ser considerada como una "hoja sagrada" y utilizada en sus ritos. 
Según algunos cronistas y misioneros, los huachipaeris eran gente muy orgullosa, conflictiva y guerrera, características que los diferenciaban de los matsigüenkas, de carácter "amable", por lo que mantuvieron una relación de intercambio y convivencia, pero no de sometimiento, con los incas; los huachipaeri brindaban plumas de aves y otros productos amazónicos, y los incas, hachas de metal. Tales contactos se prolongaron hasta inicios de la colonia.

En los primeros años de la colonia se organizaron varias expediciones con el fin de conquistar la zona, destacando las de Pedro de Candía (1538) y Álvarez Maldonado (1567-1568) al Alto Madre de Dios, y la de Atunes hasta el río Beni (1538-39). Todas estas expediciones terminaron en el fracaso.

Posteriormente, en la colonia, se implantaron las haciendas de producción de caña de azúcar con el fin de elaborar el cañazo, que, conjuntamente con la coca, tenía alta demanda en la explotación minera, especialmente en el llamado Alto Perú, donde se llegó a articular con el circuito económico de la producción minera de Potosí.

Las incursiones violentas con el "boom del caucho" desataron correrías para forzar a los nativos a ser esclavos; el resistirse era sinónimo de muerte, generándose un etnocidio; esto generó desplazamientos de poblaciones enteras, entre ellas las de los huachipaeris, que tuvieron que replegarse a las zonas más inaccesibles, ubicadas en las cabeceras de los ríos, para poder sobrevivir y perpetuar su cultura.

En la época republicana (1901), los dominicos reinician su actividad evangélica y fundan en 1908 la misión de San Luis del Manu, que estaba ubicada en la confluencia de los ríos Alto Madre de Dios y Manu, lo que hoy se conoce como Boca Manu; era un lugar donde se había establecido anteriormente un grupo de caucheros. Tras la caída del precio del caucho, la misión se retiró, al ser objeto de continuos ataques.

En 1943, los misioneros dominicos contactaron nuevamente a los harakmbut y reabrieron la misión de San Luis del Manu. Este establecimiento fue luego destruido por una inundación, y en 1958 se trasladó a Shintuya, lugar donde se encuentra actualmente la misión dominica.

Con la construcción de las carreteras, se incrementó aún más la presión sobre el pueblo huachipaeri. Inmigrantes de los andes empiezan a poblar y ocupar las áreas, abriendo los bosques para la extracción de madera y la agricultura. De esta manera, el territorio tradicional se ve afectado hasta convertirse en solo dos reducidas áreas comunales, afectándose el sistema de vida tradicional practicada durante miles de años, la caza, la pesca y la recolección de especies, la organización, la religión, los patrones de conducta y los lugares sagrados. Junto con la carretera llegaron nuevas epidemias, como la de viruela, aproximadamente por 1950, con la que murieron miles de huachipaeris. 
Los huachipaeri identifican a su actual espacio territorial titulado, donde residen, como parte del antiguo espacio territorial que les correspondía, que era mucho más amplio, como lo hemos señalado anteriormente; lo defienden porque les permite tener un espacio para ubicar sus viviendas, tener su chacras, recolectar frutos y semillas y realizar la caza y la pesca, pero este espacio es considerado como pequeño para poder realizar "normalmente sus actividades tradicionales y de reproducción de su cultura, motivo por el cual están solicitando la ampliación del territorio que ya tienen en una concesión forestal y están planeando, a futuro, solicitar otra concesión hacia las cabeceras del río Queros, con el fin de poder explotarla en la actividad turística.

La comunidad nativa de Queros tiene un área de 2924 ha, y otra área solicitada (ampliada) de 200 ha, lo que hacen un total de 3124 hectáreas. La comunidad se sitúa en la margen izquierda del río Queros, ubicada a 670 m.s.n.m. Está reconocida por Resolución Ministerial No 00184-90-DGRAA-R del 7 de marzo de 1990, y forma parte de la zona de amortiguamiento de la Reserva de Biosfera del Manu y Reserva Comunal Amarakaeri.

Existe en la población una fuerte tendencia a la migración temporal (80 \%), por motivos de trabajo y en busca de mejorar sus ingresos económicos, siendo los varones mayores de 18 años quienes van a trabajar en labores agrícolas, carpintería o en busca de realizar negocios. Un pequeño porcentaje de la población joven emigra por motivos de estudios hacia Cusco y Puerto Maldonado.

Asimismo, podemos indicar que un importante porcentaje de la población juvenil realiza sus estudios en la capital del distrito y cada año la institución educativa que existe en la comunidad se debate ante la posibilidad de cierre definitivo por falta de alumnos.

La comunidad nativa Santa Rosa de Huacaria tiene un área titulada de 36 806,25 ha, cuyas dos terceras partes aproximadamente están dentro del Parque Nacional de Manu, motivo por el cual no pueden utilizar económicamente esa área, lo que ha generado un conflictos de intereses entre la comunidad y el Parque Nacional del Manu, tensión que ha ido disminuyendo por una política de acercamiento entre el PNM y la comunidad.

En la otra tercera parte de la comunidad, donde está ubicado el centro poblado, por encontrarse en una zona de amortiguamiento del Parque Nacional de Manu, no pueden realizar la explotación intensiva de sus recursos, lo que ha llevado a que la comunidad desarrolle proyectos relacionados con el turismo que generan ingresos cada vez más importantes en la economía de las familias indígenas. 


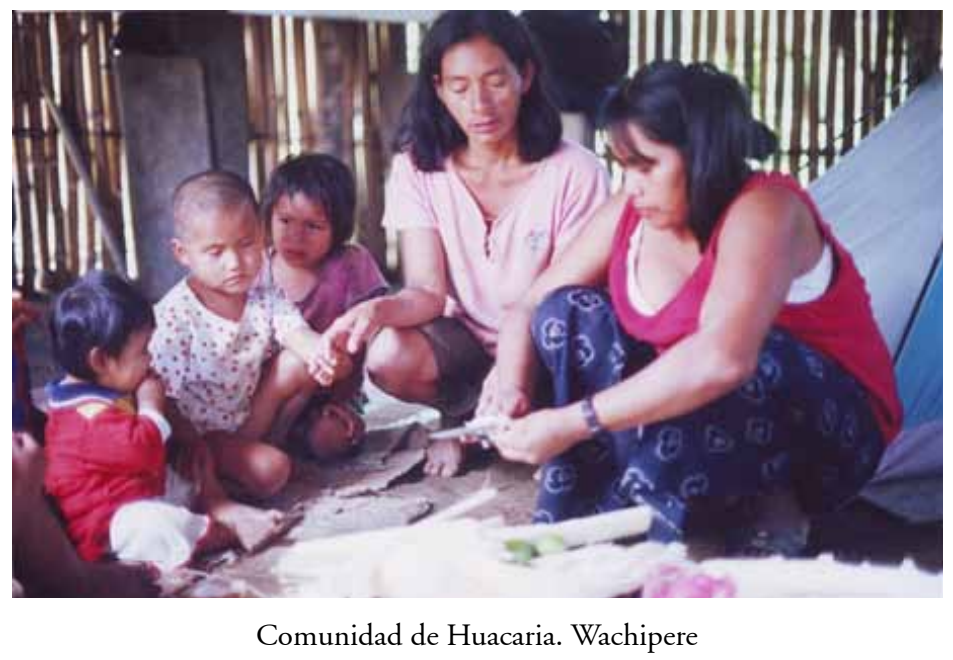

\subsection{LA ETNIA DE LOS MATSIGÜENKAS (EN CONTACTO INICIAL)}

En la Colonia, después de la derrota de los incas por los españoles, se genera "el mito del Paititi", cuyos grandes tesoros consistían en representaciones antropomorfas de sus principales dioses en oro, así como momias de los emperadores incas, que contaban con innumerables ofrendas en metales preciosos y que fueron trasladadas hacia una ciudad en la selva donde guardarían este valioso patrimonio; su ubicación fue guardado como un secreto que no llegó a conocer nadie, salvo la elite inca. Paititi viene del quechua "paikikin", que significa ciudad construida, "igual que el Cusco".

Este mito ha generado la formación de muchas expediciones hacia la selva que han fracasado, muchas de ellas en forma estrepitosa y trágica; muchos de los buscadores de esta mítica ciudad han señalado como su posible ubicación al río Piñi Piñi, y están generando el saqueo de restos arqueológicos importantes que existen en esa zona y, al mismo tiempo, están generando epidemias que afectan a las poblaciones matsigüenkas que existen en esa zona y que viven en aislamiento voluntario, debido a que en la época del caucho se replegaron a las zonas más altas del río Piñi Piñi, escapando de "las correrías" que realizaban los caucheros contra las poblaciones indígenas.

Es importante señalar esta situación de alta vulnerabilidad, de tal modo que un brote infeccioso que no sea oportunamente atendido podría afectar considerablemente su frágil densidad poblacional y convertirse nuevamente en una experiencia traumática entre la llamada "sociedad mayor" y las poblaciones indígenas.

Al crearse en 1973 el Parque Nacional del Manu, quedaron comprendidas en su ámbito 
territorial las cuencas media y alta del río Piñi Piñi, que son los lugares donde se encuentran ubicados los asentamientos familiares indígenas, en los que, se calcula hay 100 personas distribuidas entre unas 20 familias. En décadas anteriores la zona se hallaba más poblada; muchas familias han migrado hacia otras áreas del Parque Nacional del Manu, principalmente hacia la comunidad de Palotoa Teparo y a distintos asentamientos en los ríos Sotileja y Cumerjali, donde viven también matsigüenkas.

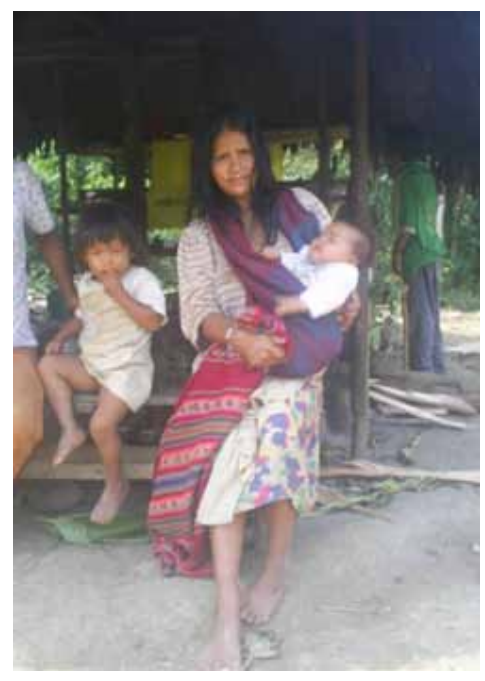

Matsigüenka del Alto Madre de Dios

\section{LOS GRUPOS ÉTNICOS DEL RÍO ARAZA (QUINCE MIL)}

Uno de los principales ríos tributarios del río Madre de Dios es el río Inambari, y afluente de este último es el río Araza, que nace en el círculo glaciar del Ausangate en el distrito de Marcapata y recorre el distrito de Camanti (Quince Mil) para desembocar en el límite departamental de Cusco, Puno y Madre de Dios.

En esta zona está ubicado el legendario cerro de Camanti, que dio origen al nombre del distrito y que fue explotado como una mina aurífera desde la época inca. Posteriormente, en la colonia y en la Republica, a partir de 1960, se desató una "fiebre" de lavado de oro en el cauce del río Araza y sus tributarios, lo que originó una migración bastante intensa de pobladores andinos hacia la ceja de selva, convirtiéndose prontamente en centros donde no solo se explotó el oro sino a las personas humanas.

Los arasaires, que pertenecen a la familia lingüística harackmbut, tenían como territorio tradicional esta área y hasta la fiebre de los lavaderos del oro, vivían apaciblemente, y organizaron 
dos comunidades dentro del territorio del distrito de Camanti, que fue reconocido por el Estado: La comunidad nativa de Huaycumbre el 28 de febrero de 1980 mediante Resolución 080-80-DRA-AA, y la comunidad de San Lorenzo, que fue reconocida el 13 de marzo de 1980 por resolución 100-80-DRA-AA.

Después de la fiebre de los lavaderos de oro, no solo han dejado los recursos de los ríos depredados sino también pueblos fantasmas como la antigua ciudad de Quince Mil, que en los años punta de explotación aurífera llego a tener un aeropuerto moderno hoy en estado de abandono. La etnia de los arasaires "en la zona quedó "casi extinguida", quedando en la comunidad de Huaycumbre como mudo testigo de ese etnocidio una sola familia y tres familias en la comunidad de San Lorenzo.

Actualmente, las dos comunidades subsisten pero sin arasaires, y son ocupadas por emigrantes andinos que mantienen el nombre porque les permite obtener algunas pequeñas ventajas en atención a su salud y de pequeñas donaciones, para enfrentar la dura pobreza que viven.

Con fines del presente trabajo, los mencionamos en ese contexto por respetar las estadísticas y los procesos históricos que se han producido.

\section{Cuadro 13}

\begin{tabular}{|l|l|l|l|l|}
\hline $\begin{array}{c}\text { Familia } \\
\text { lingüística }\end{array}$ & $\begin{array}{c}\text { Nombre } \\
\text { conocido }\end{array}$ & $\begin{array}{c}\text { Autodeno- } \\
\text { minación }\end{array}$ & Comunidad nativa & Ubicación \\
\hline Harackmbut & Arasaire & Arasaire & . Huaycumbre & $\begin{array}{l}\text { Río Huaycumbre } \\
\text { ( Marcapata) } \\
\text { Río Araza }\end{array}$ \\
\hline
\end{tabular}

Fuente: elaboración propia. Cusco, 2007. 


\section{REFERENCIAS}

- Álvarez Perca, Guillermo. Primeros pasos de las misiones dominicas de Urubamba y Madre de Dios. Lima, 2001.

- Asociación Peruana para la Conservación de la Naturaleza Apeco. Harakmbut en Ndari Territorio Harakmbut. Lima, 2000.

- Brack Egg, Antonio. NU PNUD. Amazonía Peruana, Comunidades indigenas y tierras tituladas: Atlas y base de datos. Lima, Proyecto RLA, 1997.

- Clark, Katheen. Fundación para la Conservación de la Naturaleza, "Diagnostico Socioeconómico de la zona cultural y de influencia en la reserva de la Biosfera del Manu".1999.

- Chirif, Alberto, Mora Bernasconi Carlos. SINAMOS Perú, Atlas de Comunidades Nativas. 1976.

- Gobierno del Perú. Plan de Desarrollo de los Corredores Económico-Productivos del Sur Peruano (Plan Del Sur 2006-2016). Lima, 2006.

- Chávez HeinrichMbaisik, Helbert . En la penumbra del atardecer. Lima: CAAAP, 1995.

- Instituto de Manejo de Agua y Medio Ambiente IMA. Diagnóstico Subcuenca Pilcopata. Cusco, 1994.

- Instituto Indigenista Peruano. Ministerio de Agricultura. Mapa Etnolingüistico Oficial del Perú. Lima, 1994.

- INRENA. Plan General de Manejo Forestal (PGMF). 2002.

- Municipalidad Distrital de Kcosñipata. Plan de Desarrollo Concertado del Distrito de Kcosñipata 2004-2008. PRO MANU, 2004

- Proyecto PRO MANU 2002. Implementación y seguimiento de monitoreo del impacto ambiental de actividades extractivas en la comunidad Santa Rosa de Huacaria Cusco. Informe final.

- PRO MANU. Cultura y medio ambiente en la comunidad nativa de Queros. 2004

- PLUSPETROL. Plan de contingencia antropológico para poblaciones en contacto inicial. Lima, 2003.

- Rodríguez Marleny, Helberg Heinrich. Diccionario Harakmbut-Castellano. FORTEPE.

- Torralba, Adolfo. La misión del shintuya y los amarakaeris: sedentarización y nomadismo. Lima, 1979. 
- Ugarte Vega Centeno Alfredo. Diagnóstico de la comunidad nativa Queros.. Cusco: Asociación para la Conservación de la Cuenca Amazónica (ACCA), julio 2004.

- Ugarte Vega, Centeno Alfredo. I Encuentro de shamanes y promotores de salud Pilcopata. 1998.

Álvarez, José.

- 1951. "Entre fieras salvajes y salvajes fieras". En: Misiones dominicanas del Perú. Año XXII, pp. 84-92. Lima.

- 1955. "Palotoa". En: Misiones dominicanas del Perú. Año XXXVI. pp. 262-268. Lima.

- 1961. "Bautizo a los 90 años". En: Misiones dominicanas del Perú. Año XLIII, p. 44. Lima.

Álvarez, Ricardo

- 1931. "La vieja a quien se le escapó el alma”. En: Misiones dominicanas del Perú. Año XXXII, pp. 101-103. Lima.

- 1959. "Manuel Saavedra”. En: Misiones dominicanas del Perú. Año Xl, pág. 41-53. Lima.

- Aza, Fray José Pío. 1921. "La Lengua de los salvajes machiguengas". En: Misiones dominicanas del Perú. Año III. Lima, pp. 328-331.

- 1923. "Origen de las tribus salvajes del Amazonas". En: Misiones Dominicanas del Perú. Año V, p. 392.

- 1923. "Origen de las tribus salvajes del Amazonas". En: Misiones dominicanas del Perú. Año V, No. 18, pp. 631 634. Lima.

- 1923. "La tribu machiguenga". En: Misiones dominicanas del Perú. Año V, No. 19. Lima, pp. 369-376.

- 1923. Tribus forestales del Oriente Peruano. En: Inca. Vol. 1. Lima. pp. 349-393.

- 1923. Vocabulario español machigüenga. Lima, 314 pp.

- 1923. "Vocabulario español machigüenga”. En: La Opinión Nacional.Lima, Vol. XV.

- 1924. "Crítica de la obra de Dr. Farabee: Indian Tribes of Eastern Perú". En: Misiones dominicanas del Perú. Año VI. Lima, pp. 22-27.

- 1924. "Vocabulario español machigüenga": En: Boletín de la Sociedad Geográfica de Lima. Vol. XLI. Lima, pp. 41-78.

- 1924. "Estudio sobre la lengua machiguenga". En: La Opinión Nacional. Lima, 256 pp.

- 1927. "La aglutinación en las lenguas salvajes". En: Misiones dominicanas del Perú. Año IX. Lima, pp. 126-134. 
- 1927. "Folklore de los salvajes machigüengas". En: Misiones dominicanas del Perú. Año IX pág. Lima, pp. 237-245.

- 1930. "Lengua de salvajes y civilizados" En: Misiones dominicanas del Perú. Año XII. Lima, pág. 193-199.

- 1930. "El género gramatical en las lenguas salvajes". En: Misiones dominicanas del Perú. Año XII. Lima, pp. 211- 213.

- 1931. "El verbo en las lenguas cultas y en las salvajes". En: Misiones dominicanas del Perú. Año XIII. Lima, pp. 26-33.

Baer, Gerhard.

- 1974. A particular aspect of matchiguenga shamanism (eastern Perú) male/fernale ambivalence. Paper presented at the 41 st. international congress of americanist. 17 pp. México.

- 1978. "Masken der piro Shipibo und matchiguenka (OSt-Perú)" Basel, p. 101-115, band 87-88. Separate de sonderbdruck aus den Verhandungen der naturforschenden gesellschaft.

- 1979. "Zur hentigen situation der matchiguenka und ihrer nachbarn". En: Ethnoligica No 1, pp. 37-39. Helvetica, Berne.

- 1981. "Weitere materialien su den Matsigüenka und Shipibo masken (Ost-Perú)". En: Sunderabdrick aus den Verhandungen der Nturforschenden Gesellschaft. Band 92, pp. 34-38. Basel.

Ballón Landa, Alberto

- 1917. Los hombres de la selva. Lima: Edit. La Opinión Nacional, 325 pp.

Barriales, Joaquín

- 1969/1970. "En la cuenca del río Urubamba". En: Boletín de la Sociedad Geográfica de Lima. Tomo LXXXIX. Lima.

- 1977. Matsigüenka. España: Edit. Misiones dominicas. 93 pp.

Barriales, Joaquín S. F.

- "Mitos de la cultura matsigüenka". En: Antisuyo. № 3, tomo LXXXIX. Lima, pp. 163181.

- S.F. "Mitos de la cultura matsigüenka (II)". En: Antisuyo. No 5, tomo LXXXIX. Lima, pp. 111-134.

- S.F. “Mitos de la cultura Matsigüenka (III)". En: Antisuyo. No 6. Lima: pp. 137-159. 
- Boruncle, Alfonso. "Idiomas, lenguas y dialectos en el Perú". En: América Indígena. Vol. XXXIII. No 2. México, 1973, pp. 375-399.

Bowman, I.

- 1916. The Andes of Southern Perú. New York. 1916, 348 pp.

- Brinton, Daniel. La raza americana. Buenos Aires: Edit. Nova, 1946, 361 pp.

Camino, Alejandro

- 1973. "Algunos factores del cambio socioecológico en el Alto Urubamba" en: Estudios Andinos. Vol III, No 9, pp.119-138.

- 1977. "Trueque, correrías e intercambio entre los quechuas andinos y los piro y machigüenga de la montaña peruana”. En: Amazonía Peruana. Vol. I. No 2. Lima, pp 123-140.

- 1979. "Sociocultural change in upper Urubamba": En: Peasants, Primitives \& Proletaries: The Struggle for Indenty in South America. New York, pp. 125-147.

Casevitz, Renard France Mary

- 1972. "Les Matchiguenka" en: Journal de la societe des americanistes. Tomo LXI. París, pp 215-253.

- 1974. "Los indios de la floresta tropical sudamericana. Los machigüengas" en: Boletín de la Sociedad Geográfica de Lima. Tomo XCIII, agosto- diciembre. Lima, pp. 25- 35.

- 1979. Su-acu Essai sur les cervices de I'amazonie et sur leer significtion dans les cultures indigennes antuales.

- 1980. "Inscripcion: on aspect du symbollisme matsigüenka": En: Journal de la Societe des Americanistes. Tomo LXVII. París: Musee de I'homme. pp. 261-295.

- 1984. "Fragmentos de una lección de Daniel, shamán Matshiguenga". En: Amazonía indígena. COPASL. Año 4, No 8. Lima, pp 4-6.

Cenitagoya, Vicente

- 1921. "Religión de los salvajes. Matrimonios, costumbres, un bautizo" En: Misiones dominicanas del Perú. Año III. Lima: pp. 319.

- 1922. "El río Palotoa o Shirikebenia" En: Misiones dominicanas del Perú. Año IV. Lima, pp. $447-484$.

- 1923. "Una visita a los machigüengas" En: Misiones dominicanas del Perú. Año V. Lima, pp. $35-40$. 
- 1944. Los machigüengas. Lima, 211 pp.

Chirif, Alberto; Varesse, Stefano

- 1974. Las comunidades nativas de la Selva. Lima: Centro de Estudios de Participación Popular. Lima: 99 pp.

- 1975. Diagnóstico de la Selva Central. Mimeógrafo. Lima.

Ferrero, Andrés.

- 1947. "Rutas del Urubamba. Con las tribus indígenas" En: Misiones dominicanas del Perú. Año XXVIII, pp. 164-74.

- 1948. "Rutas del Urubamba. Con las tribus indígenas" En: Misiones dominicanas del Perú. Año XXIX, pp. 2454-51, 328-7.

Ferrero, A.

- 1954. "La familia machigüenga" En: Misiones dominicanas del Perú. Año XXXV, pp. 131139; año XXXVI, p. 412-415; año XXXVII, pp. 7-10, 133-135, 214-216; año XXXVIII, pp. 8-10.

- 1957. “Testamento de un machigüenga” En: Misiones dominicanas del Perú. Año XXXVIII. Lima, pp. 43-46.

- 1960. "Suplemento al diccionario machigüenga del P. Pío Aza”. En: Misiones dominicanas del Perú. Año XLI. Lima, p. 245; pp. 19-22; No 246, pp. 13-17

- 1966. Los machigüengas. Tribu selvática del Sur Oriente Peruano. Edit. OPE. Instituto de Estudios tropicales "Pio Aza Puerto Maldonado".

Fins, Stephanie

- 1984. "Los machigüengas y las empresas misioneras" En: EXTRACTA. Centro de Investigaciones y Promoción Amazónica. Lima, pp.13-16.

- GOBIERNO REGIONAL CUSCO. INSTITUTO DE MANEJO DE AGUA Y MEDIO AMBIENTE, SHELL PROSPECTING AND DEVELOPMENT (Perú), (Gilbert Alarcón, Juan Huamán, Wáshington Loayza, Miguel Ramos, Alfredo Ugarte, Víctor Colque, María Rodríguez, Zaniel Novoa, Valerio Paucarmayta). Diagnóstico Integral y Programa de Desarrollo Sostenible de la Cuenca del Bajo Urubamba. p. 367.

- Gonzales Carre, Enrique. "Los matsigüengas de la Amazonía”. En: Bajo Urubamba. Plus Petrol.

- Guevara, V.J. "La importancia del nacionalismo de los mascos y machigüengas". En: Perú Indígena. Vol. IV. Lima, pág. 106-110. 
- INSTITUTO DE DESARROLLO DE LA AMAZONÍA, INSTITUTO NACIONAL DE CULTURA-CUSCO Y UNMSM. 2005 El Rostro Amazónico del Cusco. Lima: Fondo Editorial de la UNMSM, $471 \mathrm{pp}$.

- INSTITUTO NACIONAL DE CULTURA, MUNICIPALIDAD DISTRITAL DE KCOSNIIPATA, CRESPIAL. Diagnóstico Sociocultural de la etnia huachipaire. Cusco, 2006.

\section{INSTITUTO LINGÜÍSTICO DE VERANO}

- 1973. "Vocablos y expresiones médicas más usuales en veinte idiomas vernáculos peruanos". Documento de Trabajo No. 2. Yarinacocha, Pucallpa, Perú, 127 pp.

- 1974. Bibliografía del I.L.V. en el Perú. Suplemento No. I. Yarinacocha, Pucallpa, Perú, julio 1971- octubre 1974,16 pp.

- 1975. Informe general sobre las actividades desarrolladas por el I.L.V. en el periodo 19711974. Yarinacocha, Pucallpa, Perú, 16 pp.

- 1976. Informe general sobre las actividades desarrolladas por el I.L.V. en el año 1975. Yarinacocha, Pucallpa, Perú, 16 pp.

- 1976. Bibliografía del I.L.V. en el Perú 1946-1976. Yarinacocha, Pucallpa, Perú, 16 pp.

- 1981. Bibliografia del I.L.V. Suplemento. Enero 1977-agosto 1981.Lima: Ministerio de Educación I.L.V., 56 pp.

- 1970. "Dislocación tribal y clasificación lingüística en la zona del río Madre de Dios". En: XXXIX Congreso Internacional de Americanistas. Vol. 5. Lima: Instituto de Estudios Peruanos, pp. 185-200.

- Millones Santa Gadea, Luis. "Chiriguanos e incas: apuntes para un estudio de los grupos marginales del Tawantinsuyo". En: Arqueología y Sociedad. Vol, 7-8. Lima, 1972.

- Mora, Carlos; Chirif, Alberto. Atlas de Comunidades Nativas. Lima: Sistema Nacional de Movilidad Social (SINAMOS), 1975,119 pp.

Pereira, Fidel.

- 1942. "Leyendas machigüengas". En: Revista del Museo Nacional. Tomo XI. Lima.

- 1944. "Vocabulario de los indios machigüengas". En: Revista del Museo Nacional. Tomo XIII. Lima, pp. 93-100.

- 1944. "Chaingavane". En: Revista del Museo nacional. Tomo XIII. Lima, pp. 84-88.

Pilares Daza, José. “Espíritu Pampa”. En: Rev. Educa. Vilcabamba, Cusco, 2005. 
- Ponce de León, Federico. "El río Urubamba”. En: Revista Universitaria. Órgano de la Universidad del Cusco. Año XXIII, No. 66, tomo I. Cusco, 1934.

- Portugal Carbajal, Teodoro. La Convención. La Zona del Bajo Urubamba. Cusco, p. 199.

- Posnansky, Arthur. Antropología y sociología de las razas interandinas y de las regiones adyacentes. 2da. edición. La Paz: Edit. Renacimiento, 1938, 150 pp.

- Prince, Carlos. Idiomas y dialectos indígenas del continente hispánico.

- Reátegui, Mirca. "Bibliografía sobre antropología y arqueología de la selva del Perú". Separata del Boletín No. 73-76 de la Biblioteca Nacional. Lima, 1978, 54 pp.

- Renard-Casevitz, France-Marie. "Visión histórica de la cuenca Urubamba-Ucayali". En: Bajo Urubamba. Matsiguengas y yines. Pluspetrol.

- Rey Riveros, Edmundo. El Censo y los aborígenes selvicolas de nuestra Amazonía. Lima, 1957.

- Ribeiro, Darcy; Wise, Mary Ruth. Los grupos étnicos de la Amazonía Peruana. Lima: Instituto Lingüístico de Verano - Ministerio de Educación, 1978, 237 pp.

- Ríos, Manuel. "El Gran Parque nacional del Manu. Flora y Fauna del Perú (VI)”. En: El Serrano. Publicación de Cerro de Pasco Corporation. Vol. XXI. No 277. Lima, 1972.

- Ríos Savedra, Zaida. "Breve historia de la familia piro". En: Bajo Urubamba: matsiguengas y yines. Ed. Pluspetrol.

- Rivas T. Américo. "El Parque Nacional de Choquequirao". Revista Educa. Cusco.

Rivet, Paul.

- “Les famillas Linguistiques du Nordouest de I'Amerique du Sud". En: I'Année Linguistique. Vol. IV. París, 1912, pp. 7-154.

Rivet, Paul;Tastevin, C.

- "Les langues du Purus, du Jurua et des Regions Limitrophes". En: Anthropos. Vol XIV-XV, pp. 857-890; vol. XVI-XVII, pp. 228-235; pág. 819-828; vol. XVIII-XIX, 1919, pp. 104113.

- Rivet, Paul. "Languages de I'Amerique du sud et des Antilles". En: Les Langues du Monde. París, 1952, pp. 639-712.

- Rojas Zolezi, Martha. "Notas acerca de la Iconografía textil de los matsigüengas de la Amazonía peruana”. En: Bajo Urubamba. Matsiguengas y Yines. Pluspetrol, 2001. 
Rosell, Enrique.

- 1916. "Los machiguengas del Urubamba. Estudios etnográficos". En: Revista Universitaria del Cusco. Año V. No. 15, pp 39-48; No. 16, pp. 2-18, Cusco.

- 1917. "Monografía de la provincia de La Convención del Dpto. del Cusco". En: Revista Universitaria del Cusco, No. 19, pp. 35-50; No 20, pp. 24-33; No. 21, pp. 31-40. Cusco

- Rosengren, Dam. "Proximity and Interation: The case of the Matsigenka of the upper Urubamba, South Eastern Peru". En: Etnografica Museum, Gothemberg, Sweden. Annual Report of 1981-1983. 1983, pp. 48-63.

- Rowe, John H. "The Distribution of Indians an India Languages in Perú". En: Geographical Review. Vol. 373 No. 2, pp. 202-215, 1950.

Sabogal, José.

- 1960. "Los indígenas machiringas" (ríos Apurimac, Ene). En: Revista del Museo Nacional. Tomo XXIX. Lima, pp. 152-159.

- 1960. "Programa para la promoción de los indígenas machiringas". En: Revista Mexicana de Sociologia. Tomo XXII. México, pp. 433-439.

- Salazar Falcón, Rosal S.F. Monografía de la misión de Coribeni en el Alto Urubamba.

Samanez y Ocampo. J. B.

- 1885. Exploración de los ríos peruanos. Lima, 70 pp.

- 1885. Exploración de los ríos Apurímac, Ene, Tambo, Ucayali y Urubamba. Diario de la Expedición. Lima, 70 pp.

- Sandi, L. "Exploración del Ucayali". En: Colección de leyes, decretos, resoluciones y otros documentos oficiales referentes al Dpto. de Loreto, formado por orden Suprema por el Dr. Carlos Larraburre i Correa. Tomo II. Lima,1905, pp. 252-266.

- Santa Cruz Pachacuti Yanqui, Juan de. Crónicas peruanas de interés indígena, Madrid, 1968

- Santos, Blasco. "Colono se suicida en la selva". En: La Prensa. 15 de marzo, p. 1. Lima, 1974.

Sarasola, Monseñor S.

- 1927. "De los azafates de la vida entre salvajes". En: Misiones dominicanas del Perú. Año IX. Lima, pp. 227-230.

- 1933. “Extraña epidemia en la región del Urubamba”. En: Misiones dominicanas del Perú. 
Año XV. Lima, pp. 2-9.

- 1934. "Entre machigüengas". En: Misiones dominicanas del Perú. Año XVI. Lima, pp. 148-149.

- 1935. "Antonia, machigüenga, tipo, vestidos, adornos". En: Misiones dominicanas del Perú. Año XVII. No. 86. Lima, pp. 3-10.

- 1935. "La gran pesca entre machigüengas". En: Misiones dominicanas del Perú. Año XVII. No. 87. Lima, pp. 48-56.

- 1938. "Cómo son las misiones del Madre de Dios". En: Misiones dominicanas del Perú. Año XX. Lima, pp. 1-12.

- 1938. "Gregorio, machigüenga". En: Misiones dominicanas del Perú. Año XX. Lima, pp. $71-75$.

- 1941. "Colonización y misiones. Vías de comunicación". En: Misiones dominicanas del Perú. Año XXIII. Lima, pp. 121-126.

Savoy, Gene

- 1970. Vilcabamba. Last City of the Incas. London: Robert Hale.

- 1970. Antisuyo. The Search for the Last Cities of the Amazon. New York: Simon and Schuster, 220 pp.

- Scipion Llona, P. "Reseña histórico-geográfica de los ríos Paucartambo y madre de Dios". En: Boletín de la Sociedad Geográfica de Lima. Vol. 14. Lima, 1903, pp. 63-176.

- Schuller, R.R. Ed. "Documentos para el estudio de la historia de las misiones franciscanas en el Perú Oriental”. En: Revista Histórica. Tomo III. Lima, 1908, pp. 165-189.

Schwab, Federico

- 1936. "Bibliografía de etnología peruana". En: Boletín Bibliográfico de la Biblioteca Central de la Universidad Nacional Mayor de San Marcos. No. 1, 2. Lima, pp. 3-4, 1-27, 4-28, $101-$ 115.

- 1938. "Bibliografía de antropología peruana 1936-1937". En: Boletín Bibliográfico de la Biblioteca Central de la Universidad Nacional Mayor de San Marcos. No. 1. Lima, pág. 4885.

- 1942. Bibliografia Etnológica de la Amazonía peruana. Lima.

- Serrano C., Ricardina S. F. Sistema de trabajo en La Convención. Archivo Histórico del Cusco. 
- Shell R., Olive y Wise, Mary Ruth. Grupos idiomáticos del Perú. 2da. edic. Universidad Nacional Mayor de San Marcos. Instituto Lingüístico de Verano. Lima, 1971, 48 pp.

- Solís, Gustavo. Fonología machiguenga (arawak). Universidad Nacional Mayor de San Marcos. Centro de Investigación de Lingüística Aplicada. Lima, 1973, 81 pp.

- Soto, Julio. "Ecología y salud en nativos machigüengas". En: Amazonía Peruana. Vol. III No 6. Revista semestral del Centro Amazónico de Antropología y Aplicación Práctica. Lima, 1982.

- Tello Abanto, Rodolfo. Los matsigüenga del río Piñi Piñi. Experiencias iniciales de contacto cultural. Promanu, s/f.

- Ugarte Gallegos, Mary. Elproblema de la colonización en la provincia de La Convención, Cusco. Tesis. Universidad Nacional del Cusco, 1959.

- Ugarte Vega Centeno, Alfredo; Ismael Hernández. "Los matsigüengas del Bajo Urubamba”. En: Bajo Urubamba: matsiguengas y yines. Pluspetrol, 2001.

- Ugarte Vega Centeno, Alfredo. "Las etnias del Bajo Urubamba". En: La zona del Bajo Urubamba.

- Uriarte Lope, Luis M. "Poblaciones nativas de la Amazonía peruana". En: Amazonía Peruana. Vol. 1, No. 1, pp. 9-58. Lima: Centro Amazónico de Antropología y Aplicación Práctica, 1976. 